Research Article

\title{
Stability Analysis and Control Strategy for the Chained Propagation of Delay or Disruption Risk in a Port-Hinterland Service Network
}

\author{
Haibo Kuang $\mathbb{D}^{1,2}$, Pengfei Zhang $\mathbb{D}^{1,3}$ Bing Han $\mathbb{D}^{\mathbb{D}},{ }^{1,2}$ and Peng Ouyang $\mathbb{D}^{4}$ \\ ${ }^{1}$ Collaborative Innovation Center for Transport Studies, Dalian Maritime University, Dalian 116026, China \\ ${ }^{2}$ Shipping Economics and Management College, Dalian Maritime University, Dalian 116026, China \\ ${ }^{3}$ Transportation Engineering College, Dalian Maritime University, Dalian 116026, China \\ ${ }^{4}$ School of Economics and Management, Dalian University of Technology, Dalian 116024, China
}

Correspondence should be addressed to Pengfei Zhang; haerbinzpf@163.com

Received 23 September 2020; Revised 30 January 2021; Accepted 11 February 2021; Published 24 February 2021

Academic Editor: Bekir Sahin

Copyright (C) 2021 Haibo Kuang et al. This is an open access article distributed under the Creative Commons Attribution License, which permits unrestricted use, distribution, and reproduction in any medium, provided the original work is properly cited.

In a port-hinterland service network (PHSN), the occurrence of delays or disruption risks in the ports could impose serious impacts on carriers, nodes in hinterlands, or even the entire port-hinterland service network. To study how such risks are generated, propagated, and effectively controlled in the port-hinterland service network, this paper builds a model for the chained propagation of network risks that is consistent with the characteristics of the port-hinterland service network after analysing the risk factors and the risk-generating path by using the fuzzy analytic hierarchy process (FAHP) framework. On the premise of model stability analysis, the paper analyses the elasticity of carriers and ports to the infected proportion of nodes in the hinterlands, infection rate, and recovery rate in order to obtain the optimal control strategy and control coefficient, and the paper finally validates the model through a simulation analysis under a real case. The research shows that external factors causing delay or disruption risk are more important than internal factors, while the occurrence probability of external factors is lower than that of internal factors. There are four equilibrium points in this system. When the equilibrium conditions are met, the infected proportion of carriers and ports gradually approaches zero or narrows to a fixed ratio, and there is only one no-epidemic point. In the equilibrium conditions, when the infected proportion of inland ports is greater than a certain threshold, the infected proportion of carriers and ports decreases with an increase in the infected proportion of inland ports. Moreover, it is determined that increasing the recovery rate is the most effective and direct control measure. The results of this study provide new insights for the risk control of port-hinterland service network managers and participants.

\section{Introduction}

Maritime transportation plays a significant role in international trade. Approximately, $80 \%$ of the international trade volume and $55 \%-67 \%$ of the international trade value are completed through maritime transportation [1]. In recent years, the advocacy of low carbon emissions and low transportation costs has highlighted the great advantages of nodes in the hinterland, such as distribution centres, logistics parks, and dry ports. With this background, porthinterland service networks (PHSNs), with ports at the core and nodes in the hinterland and carriers as the supplement, have gradually taken shape. Currently, approximately $90 \%$ of the trade of goods is completed through such service networks [2]. However, the complex service process, changeable environment, and diverse participants all have negative impacts on the stability and efficiency of the port-hinterland service network and nodes. Some self-evident cases include the Japan Earthquake and Tsunami of 2011, the strike on the U.S. West Coast in 2012, and the Tianjin Port explosion in $2015[3,4]$. When the service node is at risk, the functions of the port-hinterland service network will be affected. Nodes in PHSNs with a damaged function can lead to a delay or disruption risk of itself or even the entire service network, 
and such an impact might spread and involve other participants in the upstream and downstream service sectors, leading to immeasurable economic losses. Therefore, understanding how the risk spreads in the port-hinterland service network based on the key factor analysis for delay or disruption risk and how to control it are valuable lessons for relevant participants and managers.

During cargo transportation, risks exist in different links of the chain in various forms. Although scholars have put different emphases in research and hold different opinions, the risks can generally be categorized as natural disasters, fires, terrorist attacks, strikes, human errors, technical faults, and financial risks [5-8]. However, current studies lack a ranking of these factors. After evaluation, most scholars have reached the consensus that natural disasters and strikes are the two risk categories that could seriously affect cargo transportation services [9-11]. Hazard recognition and risk assessment serve as useful references for managers in risk recognition and precautions. To provide effective risk response strategies and improve the stability of the porthinterland service network, the design of a port-hinterland service network based on the risks, contract design among the participants, and risk investment are also research emphases [12-14]. Therefore, research on the port-hinterland service network risk has mainly been the risk factor recognition, risk assessment, and network design and optimization, while research on how the risk spreads in the network, the influence on the upstream and downstream carriers, and what effective measures can be adopted is very limited. A port-hinterland service network is a supply chain network that in essence offers logistics services [15]. Therefore, research on risk propagation in the supply chain sector provides a reference for this paper [16-18]. However, the current research only explores how risks spread in certain links in the supply chain and does not take their forms or the spreading time into consideration. In addition, there is no further discussion on optimized control strategies.

In light of this, this paper focuses on a port-hinterland service network consisting of the port, the nodes in the hinterland, and the carrier and aims to establish a model of chained risk propagation based on the classic susceptibleinfected-removed (SIR) model after analysing the delay or disruption risk factors and generating path. It also analyses the propagation and stability of risks among the three types of participants and throughout the entire port-hinterland service network from a dynamic perspective. Taking the equilibrium point of risk propagation as the optimized object, this paper provides an optimal control strategy and obtains the optimal control coefficient by analysing the elasticity of the equilibrium point to propagation incidence and the recovery rate. Finally, we validate this model by using real data. The scope of this study is illustrated in Figure 1. The research results are of reference value and can serve as a reliable guide for the risk management of a porthinterland service network.

The remainder of this paper is organized as follows. Section 2 briefly reviews the related literature. Risk factors and the path are analysed in Section 3. In Section 4, we propose a chained risk propagation model for a port-hinterland service network. Mathematical analyses of this model are also provided. To investigate the best control method of this model, elasticity analyses for different parameters are laid out in Section 5. In Section 6, we propose a method to determine the best coefficient of risk control under constrained resources. A numerical simulation based on real data validates this model in Section 7. Finally, conclusions are presented in Section 8.

\section{Literature Review}

The literature referred to in this paper is mainly based on three perspectives, namely, studies on the risk factors for a port-hinterland service network, optimization control of port-hinterland service network risks, and research on supply chain risk propagation.

2.1. Risk Factor Analysis. The analysis of risks in port-hinterland service networks has been a research focus for scholars in recent years. Through actual case analyses and investigations from multiple perspectives, many researchers have discovered some factors that may lead to risks in porthinterland service networks, such as ports, transportation, and logistics. They also performed a detailed analysis of the relationship between the risk factors and their importance via new methods. Wan adopted the fuzzy Bayesian method to assess the risk factors in a maritime transportation supply chain network and concluded that dangerous cargo, oil price fluctuations, fierce competition, and the market environment are significant risk factors [19]. Rahman found factors that may lead to delayed bulk cargo transportation from four perspectives, including the port, carrier, and owner of goods, and noted that accurate weather forecasting and tide predictions can reduce the probability of delay [20]. Loh recognized and analysed the interruption risk factors in port service supply chain networks through questionnaires and the fuzzy comprehensive assessment method. The conclusion was that some key factors that cause transportation service interruption include port or hinterland congestion, insufficient equipment and facilities, broken port infrastructure, and lower port loading and unloading capabilities [21]. Cho Lee adopted resource-based view (RBV) and structural equation modelling (SEM) methods to analyse the relevant cases and data and concluded that infrastructure and operating capabilities are two key factors for decreasing maritime transportation risks while increasing the transportation volume [22]. Fartaj developed integrated bestworst (BWM) and rough strength-relation (RSR) analysis methods and analysed the interruption factors in a porthinterland service network to study their relationship [23]. The system dynamics is applied by Kwesi in both the analysis of the relationship between the risk factors in the port and the maritime transportation logistics network, as well as in the study of the response of risk prevention on the basis of different scenarios [24]. Lam determined that natural disasters and strikes are two vital factors causing port service interruptions through the analysis of port service 


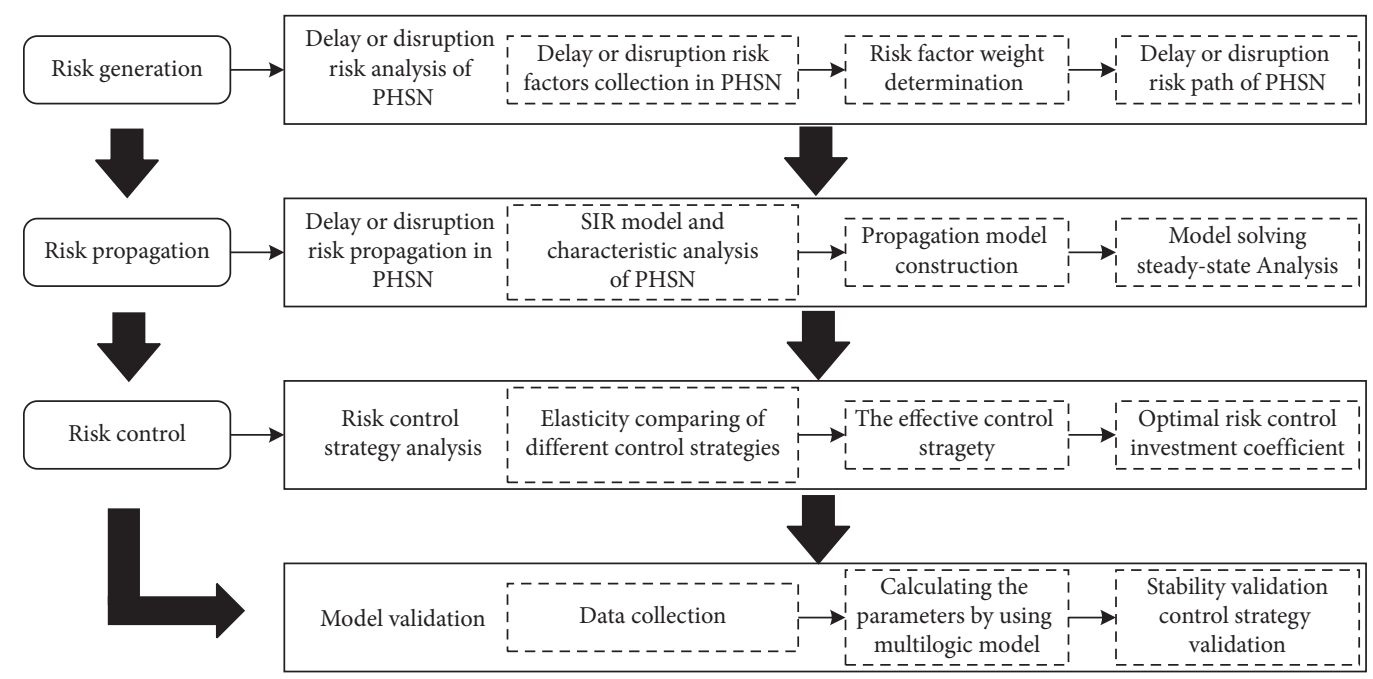

FIGURE 1: Scope of the research progress.

interruption data in Asia from 1900. Another finding is that natural disasters tend to cause greater losses. He also developed prevention and response strategies targeted at different situations [25].

2.2. Risk Optimization Control. The risk control of porthinterland service networks is another research emphasis for scholars. They have conducted research on how to improve the elasticity and stability of port-hinterland service networks from the perspectives of network model design, risk investment strategy, game theory, and portfolio approaches. Gonzalez concluded that a hinterland or inland port can greatly improve the stability of the port-hinterland service network after analysing the Swedish port conflict between 2016 and 2017 [26]. Asadabadi proposed an optimized model based on random planning, bilevel programming, and game model theory for addressing the uncertainties in the transportation time and trade volume with ports in maritime transportation [27]. Hosseini shifted the research emphasis from risk protection and prevention to risk. He constructed a risk model in the Bayesian network by taking risk absorption, risk adaption, and recovery capability into consideration and applied the model in a multimodal porthinterland service network [28]. Torabi took the business continuity and capabilities of port suppliers and contracts with backup suppliers into consideration. A two-phase random planning model was proposed to address supplier selection and assignment, to respond to operation and disruption risks in the supply chain and to improve the elasticity of the port supply chain network [29]. Liu Gong conducted research on investment strategies for risk prevention in four situations against the background of port competition. As proven by the results, cooperation between two ports could increase investments in risk prevention compared with their complementary relationship [4]. Xiao developed an integrated risk prevention investment model based on the risk incidence and return on investment with landlord ports as the research subject. The results showed a positive correlation between investment time and risk incidence [30]. Goldbeck put forward a multiphase random planning model. To improve the elasticity of the logistics network response to risks, he optimized ex-ante investment decision-making and post resource allocation in the logistics supply chain [31]. Portfolio approaches are another important perspective in risk control and mitigation. T. Sawik, as a representative scholar, has made great efforts in this research field. In 2017, a computationally efficient portfolio approach to supplier selection combining decisions made before, during, and after the disruption was proposed [32], and then a risk-neutral or risk-averse supply portfolio approach was developed from the dynamic perspective in the same year [33]. In 2019, an innovative portfolio approach and stochastic MIP formulations with an embedded network flow problem were developed for the selection of primary and recovery suppliers and assembly plants in the presence of supply chain disruption risks [34]. The next year, a twoperiod decision-making model was developed for the selection of resilient supply portfolios in a multitier supply chain under disruption risks [35]. The above studies provide many references for delay or disruption risk mitigation and control.

2.3. Risk Propagation. Determining the risk propagation mechanism in the supply chain network and its factors has great significance in choosing effective precautionary measures. The supply chain network structure, network features, and risk propagation are prominent research topics. Huo proposed a propagation model of supply chain risks on the basis of herd effects and risk preference when risks occur. The research results showed that the spreading threshold is closely related to the network structure, public psychology, and risk preference [36]. Li explored the network structure in maintaining supply chain network elasticity from the perspective of related features of the complex network [37]. Zhang developed a risk cascade propagation model to explore how risks could propagate in two 
independent networks [38]. Tang then constructed a risk propagation model with the equipment supply chain network as the research subject. Additionally, he conducted a numerical analysis of the risk propagation phenomenon and robustness under different risk scenarios [39]. The epidemic model is favoured by many scholars in the research of supply chain network risk propagation. Liu developed an unawareness-awareness-unawareness and susceptible-infected-susceptible (UAU-SIS) model in the agent heterogeneity of the network and explored how agents affect one another as well as the impact risk propagation in the network [40]. It turned out that the extent of cooperation will increase the incidence of risk propagation and reduce the threshold of risk propagation. The increased intensity of local risk propagation will raise the incidence of risk propagation. Yang Kang incorporated the susceptible-infected-recovered (SIR) model into supply chain risk propagation research. He took an example of "small-world" networks and performed a simulation analysis of the model from the entire supply chain network perspective. The research results showed that the improved risk response capability will better control the spread of risks in the supply chain network [41]. Zhao Meng built a breakout-susceptiblerecovery-risk propagation (BSR-RP) model of supply chain network risk propagation to determine the risk propagation patterns and factors in the supply chain. As demonstrated by the research, the larger the influence a company has, the wider and quicker the risks will propagate in the supply chain network [42]. In addition to risk propagation research in the supply chain network by using modelling and simulation methodologies, many scholars have obtained supply chain network risk propagation mechanisms based on actual cases and put forward targeted response strategies $[43,44]$.

2.4. Research Gaps. Although showing some good insights, the aforementioned studies, when applied to port-hinterland service network risk propagation and control, still reveal the following specific research gaps:

(a) Previous research on risk factor analysis is concentrated on the domains of marine, transportation, logistics enterprises, ports, shipping, etc., lacking a focus on port-hinterland service networks comprising ports, carriers, and nodes in the hinterland. In addition, most of the existing studies only categorized the risk factors without weight and rank, so it is confusing for readers to understand the importance of the risk factors and the emergence of a delay or disruption risk.

(b) The current research on delay or disruption risk focused on the static risk in one agent participating in the PHSN, while the risk was always in a dynamic state. It also ignored the risk propagation from the perspective of the PHSN system. Regarding risk control, studies have mainly used programming methods to design risk-averse networks, lacking control analysis from systemic and dynamic perspectives.
To fill the research gaps, this paper integrates a risk factor analysis with risk propagation and risk control to address the above issues. We first collect all the factors causing delay or disruption risk in PHSNs and then screen and rank them by the FAHP framework. We next aim to construct a model for chained risk propagation in line with the characteristics of the port-hinterland service network and to conduct research on the risk propagation process and optimized control strategies from systemic and dynamic perspectives.

\section{Risk Factor Identification and Analysis in PHSN}

Risk existing in port-hinterland service networks comes in different forms, such as damage quality risk, time risk, and financial risk. In our study, we mainly focus on the delay or disruption risk of time. Like most of the risk management literature, we assume that events are the decisive factors that determine risk [45], so the factor identification of delay or disruption risk is considered important in risk management. Although many scholars have studied the risk factors in port-hinterland service networks from many aspects, related studies still lack an importance or ranking analysis in these risk factors, so in this section, we use the fuzzy analytic hierarchy process (FAHP) framework to assess and rank the factors causing a delay or disruption risk in port-hinterland service networks by referencing previous research [46] to enhance understanding of the risk occurrence process.

3.1. Fuzzy AHP (FAHP) Methodology. In this study, the extent FAHP is utilized, which was originally introduced by (Chang, 1996) [47]. Let $X=\left\{x_{1}, x_{2}, x_{3}, \ldots, x_{n}\right\}$ an object set, and $G=\left\{g_{1}, g_{2}, g_{3}, \ldots, g_{n}\right\}$ be a goal set. According to the method of Chang's extent analysis, each object is taken and extent analysis for each goal performed respectively. Therefore, mextent analysis values for each object can be obtained, with the following signs: $M_{g i}^{1}, M_{g i}^{1}, \ldots, M_{g i}^{m}, i=1,2, \ldots, n$, where $M_{g i}^{j}(j=1,2, \ldots$, $m, i=1,2, \ldots, n)$ all are TFNS. The steps of Chang's extent analysis can be given as in the following:

Step 1: the value of fuzzy synthetic extent with respect to the $i$ th object is defined as

$$
S_{i}=\sum_{j=1}^{m} M_{g i}^{j} \otimes\left[\sum_{i=1}^{n} \sum_{j=1}^{m} M_{g i}^{j}\right]^{-1},
$$

and to obtain $\sum_{j=1}^{m} M_{g i}^{j}$, the fuzzy addition operation of $m$ extent analysis values for a particular matrix is performed such as

$$
\sum_{j=1}^{m} M_{g i}^{j}=\left(\sum_{j=1}^{m} l_{j}, \sum_{j=1}^{m} m_{j}, \sum_{j=1}^{m} u_{j}\right) .
$$

And to obtain, the fuzzy addition operation of $M_{g i}^{j}(j=1,2, \ldots, m)$ values is performed such as 


$$
\sum_{i=1}^{n} \sum_{j=1}^{m} M_{g i}^{j}=\left(\sum_{i=1}^{n} \sum_{j=1}^{m} l_{j}, \sum_{i=1}^{n} \sum_{j=1}^{m} m_{j}, \sum_{i=1}^{n} \sum_{j=1}^{m} u_{j}\right) .
$$

And then the inverse of the vector above is computed, such as

$$
\left[\sum_{i=1}^{n} \sum_{j=1}^{m} M_{g i}^{j}\right]^{-1}=\left(\frac{1}{\sum_{i=1}^{n} \sum_{j=1}^{m} l_{j}}, \frac{1}{\sum_{i=1}^{n} \sum_{j=1}^{m} m_{j}}, \frac{1}{\sum_{i=1}^{n} \sum_{j=1}^{m} u_{j}}\right) .
$$

Step 2: as $M_{1}=\left(l_{1}, m_{1}, u_{1}\right)$ and $M_{2}=\left(l_{2}, m_{2}, u_{2}\right)$ are two triangular fuzzy numbers, the degree of possibility of $M_{1}=\left(l_{1}, m_{1}, u_{1}\right) \geq M_{2}=\left(l_{2}, m_{2}, u_{2}\right)$ is defined as

$$
V\left(M_{1} \geq M_{2}\right)=\sup _{x \geq y}\left[\min \left(\mu_{M_{1}}(x), \mu_{M_{2}}(y)\right)\right] .
$$

And it can be expressed as follows:

$$
\begin{aligned}
& V\left(M_{1} \geq M_{2}\right)=\operatorname{hgt}\left(M_{1} \cap M_{2}\right)=\mu_{M_{1}}(d), \\
& \mu_{M_{1}}(d)= \begin{cases}1, & m_{1} \geq m_{2}, \\
\frac{l_{2}-u_{1}}{\left(m_{1}-u_{1}\right)-\left(m_{2}-l_{2}\right)}, & m_{1} \leq m_{2}, u_{1} \geq l_{2}, \\
0, & \text { otherwise. }\end{cases}
\end{aligned}
$$

Figure 2 illustrates the above equation where $d$ is the ordinate of highest intersection point $D$ between $\mu_{M_{1}}$ and $\mu_{M_{2}}$ to compare $M_{1}$ and $M_{2}$, and we need both the values of $V\left(M_{1} \geq M_{2}\right)$ and $V\left(M_{2} \geq M_{1}\right)$.

Step 3: the degree possibility for a convex fuzzy number to be greater than $k$ convex fuzzy numbers $M_{i}(i=$ $1,2, \ldots, n)$ can be defined by

$$
\begin{aligned}
& V\left(M \geq M_{1}, M_{2}, \ldots, M_{k}\right) \\
& =V\left[\left(M \geq M_{1}\right) \text { and }\left(M \geq M_{2}\right) \text { and } \ldots\left(M \geq M_{k}\right)\right] \\
& =\min V\left(M \geq M_{i}\right), \quad i=1,2, \ldots k .
\end{aligned}
$$

Assume that for $k=1,2, \ldots, n, k \neq i$. Then, the weight vector is given by

$W^{\prime}=\left(d^{\prime}\left(A_{1}\right), d^{\prime}\left(A_{2}\right), \ldots, d^{\prime}\left(A_{n}\right)\right)^{T}$, where $A_{i}(i=$ $1,2, \ldots, n)$ are $n$ elements.

Step 4: via normalization, we get the normalized weight vectors:

$W=\left(d\left(A_{1}\right), d\left(A_{2}\right), \ldots, d\left(A_{n}\right)\right)^{T}$, where $W$ is a nonfuzzy number.

3.2. Determination of Specific Factor Weights. Factors that cause delay or disruption risk in port-hinterland service networks have been collated from previous studies [19, 48, 49] and responses from industry experts. The lists of categories and factors are shown in Table 1. The identified factors have been grouped into three hierarchies, where each

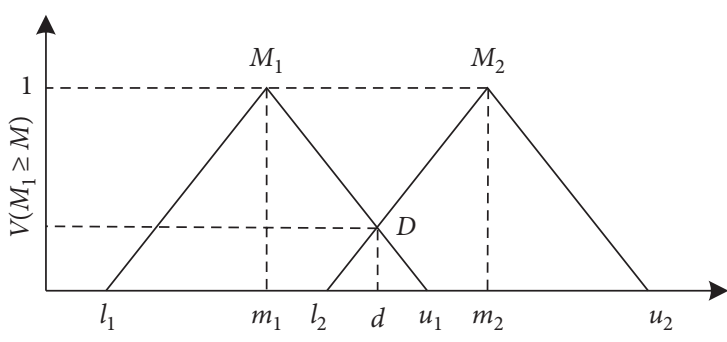

FIgURE 2: The intersection between $M 1$ and $M 2$.

hierarchy consists of different kinds of factors, which are explained in detail below. The final list contains thirty-five factors that are spread across the eight categories (see Table 1). In reality, triangular fuzzy numbers (TFNs) are frequently used, as given in Table 2 .

After calculation following the above-discussed FAHP steps, the weights of the factors and subfactors are determined. The results of the analysis using the AHP technique under fuzzy conditions are shown in Table 3 . The results consist of the rank of the categories, the rank of the factors within each category, and global ranks of all factors across all the categories. The abbreviations FC, RW, GW, RR, and GR indicate the factor, the relative weights, global weights, relative rank, and global rank, respectively, as shown in Table 3.

Table 3 indicates that external factors $(E)$ are more important than internal factors $(F)$ because external factors are not always under control and occur suddenly. Within the external factors, natural factors are key to causing delays or disruption risks. The second important category is political, and the next most important category is the market. Internal factors are also important aspects of delay or disruption risk, which comprise the descending importance rank factor, namely, human, infrastructure, process, management, and information. The rank and weight of each subfactor in hierarchy three are also illustrated in this table. From a global perspective, terrorism (E21), earthquake $(E 12)$, political unrest (E23), infectious diseases (E14), and fire (E13) are the top five factors. By analysing the weight and rank carefully, the path from risk factors to delay or disruption risk is noticeable, as illustrated in Figure 3.

\section{The Risk Propagation Model}

4.1. Problem Description. The port-hinterland service network comprises nodes in the hinterlands, carriers, and ports. Exported goods will be carried to the port by carriers from nodes in the hinterlands. In this service process, a delay or disruption risk occurring to any party could exert an impact on other parties upstream and downstream, thus leading to delays or disruption of the inland transport service. In the port-hinterland service network, the methods of delay or disruption risk propagation can be categorized into chain type, radiation type, and concentration type. The research subject of this paper is risk propagation in the chain type. Chained risk propagation in the port-hinterland service network refers to the following: when delay or disruption risk occurs in the port, their negative impacts will involve a 
TABLE 1: The risk factors in port service network.

\begin{tabular}{|c|c|c|}
\hline Factors (I) & Subfactors (II) & Risk subfactors (III) \\
\hline \multirow{12}{*}{ External $(E)$} & \multirow{5}{*}{ Natural $(E 1)$} & Extreme weather $(E 11)$ \\
\hline & & Earthquake $(E 12)$ \\
\hline & & Fire $(E 13)$ \\
\hline & & Infectious diseases $(E 14)$ \\
\hline & & Terrorism $(E 21)$ \\
\hline & \multirow[t]{2}{*}{ Political (E2) } & Military conflict (E22) \\
\hline & & Political unrest (E23) \\
\hline & \multirow{5}{*}{ Market (E3) } & Increase of costs $(E 31)$ \\
\hline & & Fierce competition (E32) \\
\hline & & Monopoly (E33) \\
\hline & & Economic crisis or unattractive markets (E34) \\
\hline & & Bankruptcy (E35) \\
\hline \multirow{23}{*}{ Internal $(F)$} & \multirow{6}{*}{ Human $(F 1)$} & Strikes $(F 11)$ \\
\hline & & Traffic accidents $(F 12)$ \\
\hline & & Fault in cargo handling $(F 13)$ \\
\hline & & Explosion $(F 14)$ \\
\hline & & Operators' low service level $(F 15)$ \\
\hline & & Insufficient knowledge $(F 16)$ \\
\hline & \multirow{5}{*}{ Process $(F 2)$} & Cargos or documents are detained by government departments (F21) \\
\hline & & Poor communication $(F 22)$ \\
\hline & & Transportation of dangerous goods $(F 23)$ \\
\hline & & Payment delay from partners or shippers $(F 24)$ \\
\hline & & Unrealized contract with partners $(F 25)$ \\
\hline & \multirow{4}{*}{ Infrastructure $(F 3)$} & Machine failure or breakdown $(F 31)$ \\
\hline & & Inadequate railway or road network capacity $(F 32)$ \\
\hline & & Cargo handling infrastructure limitations (F33) \\
\hline & & Transport equipment insufficient capacity (F34) \\
\hline & \multirow{4}{*}{ Management $(F 4)$} & Unreasonable schedule $(F 41)$ \\
\hline & & Misplaced routing $(F 42)$ \\
\hline & & Information asymmetry or incompleteness (F43) \\
\hline & & Insufficient risk awareness or management (F44) \\
\hline & \multirow{4}{*}{ Information $(F 5)$} & Transmit essential information on delayed or wrong time (F51) \\
\hline & & IT infrastructure breakdown or crash $(F 52)$ \\
\hline & & Unsuitable operations on IT infrastructures (F53) \\
\hline & & Internet connection problem (F54) \\
\hline
\end{tabular}

TABle 2: Assessment scale.

\begin{tabular}{lcc}
\hline Semantic attributes & Assigned TFN & Assigned TFN reciprocal \\
\hline Just equal & $(1,1,1)$ & $(1,1,1)$ \\
Equally important (EI) & $(1 / 2,1,3 / 2)$ & $(2 / 3,1,2)$ \\
Weakly more important (WMI) & $(1,3 / 2,2)$ & $(1 / 2,2 / 3,1)$ \\
Strongly more important (SMI) & $(3 / 2,2,5 / 2)$ & $(2 / 5,1 / 2,2 / 3)$ \\
Very strongly more important (VSMI) & $(2,5 / 2,3)$ & $(1 / 3,2 / 5,1 / 2)$ \\
Absolutely more important (AMI) & $(5 / 2,3,7 / 2)$ & $(2 / 7,1 / 3,2 / 5)$ \\
\hline
\end{tabular}

carrier downstream and then the nodes in the hinterland, as shown in Figures 4 and 5. The research, based on the classic susceptible-infected-removed (SIR) model [50, 51], categorizes the nodes in the hinterland, carrier, and port into the susceptible class $S(t)$, spread class, and immune class $R(t)$, as shown in Figure 5., IA, RA, SB, IB, RB, SC, $I(t) \mathrm{IC}$, and RC represent the susceptible class $S(t)$, spread class $I(t)$, and immune class of the hinterland, carrier, and port, respectively. $\beta_{2}$ refers to the risk propagation incidence between the hinterland and the carrier; $\beta_{3}$ denotes the risk propagation incidence between the carrier and the port; $\alpha_{2}$ stands for the recovery rate of the carrier; and $\alpha_{3}$ means the recovery rate of the port.
Since the number of carriers, nodes in the hinterlands, and ports are limited by the market capacity, it is similar to biological population growth under a certain food and space, so we assume that the number of each kind of agent follows a logistic function that is introduced to mark the changes in the quantity. This function is widely used in the simulation domain [52]:

$$
S(t)=\frac{K S_{0} e^{r t}}{K+S_{0}\left(e^{r t}-1\right)} .
$$

In the equation, $S_{0}$ represents the initial quantity, $r$ is the growth rate, and $K$ is the market capacity, namely, 
TABLE 3: Final ranking for specific risk factors.

\begin{tabular}{|c|c|c|c|c|c|c|c|c|c|c|c|c|}
\hline FC & RW & $\mathrm{RR}$ & FC & RW & $\mathrm{RR}$ & $\mathrm{GW}$ & GR & $\mathrm{FC}$ & RW & $\mathrm{RR}$ & GW & GR \\
\hline \multirow{12}{*}{$E$} & \multirow{12}{*}{0.5588} & \multirow{12}{*}{1} & \multirow{4}{*}{$E 1$} & \multirow{4}{*}{0.3888} & \multirow{4}{*}{1} & \multirow{4}{*}{0.2173} & \multirow{4}{*}{1} & $E 11$ & 0.0855 & 4 & 0.0186 & 23 \\
\hline & & & & & & & & $E 12$ & 0.3890 & 1 & 0.0845 & 2 \\
\hline & & & & & & & & $E 13$ & 0.2361 & 3 & 0.0513 & 5 \\
\hline & & & & & & & & $E 14$ & 0.2894 & 2 & 0.0629 & 4 \\
\hline & & & \multirow{3}{*}{$E 2$} & \multirow{3}{*}{0.3679} & \multirow{3}{*}{2} & \multirow{3}{*}{0.2056} & \multirow{3}{*}{2} & E21 & 0.4830 & 1 & 0.0993 & 1 \\
\hline & & & & & & & & $E 22$ & 0.1615 & 3 & 0.0332 & 11 \\
\hline & & & & & & & & $E 23$ & 0.3555 & 2 & 0.0731 & 3 \\
\hline & & & \multirow{5}{*}{ E3 } & \multirow{5}{*}{0.2433} & \multirow{5}{*}{3} & \multirow{5}{*}{0.1360} & \multirow{5}{*}{3} & E31 & 0.0926 & 5 & 0.0126 & 27 \\
\hline & & & & & & & & E32 & 0.1447 & 4 & 0.0197 & 21 \\
\hline & & & & & & & & E33 & 0.2011 & 3 & 0.0273 & 14 \\
\hline & & & & & & & & E34 & 0.2622 & 2 & 0.0356 & 9 \\
\hline & & & & & & & & E35 & 0.2994 & 1 & 0.0407 & 7 \\
\hline \multirow{23}{*}{$F$} & \multirow{23}{*}{0.4412} & \multirow{23}{*}{2} & \multirow{6}{*}{$F 1$} & \multirow{6}{*}{0.3010} & \multirow{6}{*}{1} & \multirow{6}{*}{0.1328} & & $F 11$ & 0.2782 & 1 & 0.0369 & 8 \\
\hline & & & & & & & & $F 12$ & 0.2131 & 3 & 0.0283 & 13 \\
\hline & & & & & & & & $F 13$ & 0.1644 & 4 & 0.0218 & 20 \\
\hline & & & & & & & 4 & $F 14$ & 0.2505 & 2 & 0.0333 & 10 \\
\hline & & & & & & & & $F 15$ & 0.0077 & 6 & 0.0010 & 35 \\
\hline & & & & & & & & $F 16$ & 0.0860 & 5 & 0.0114 & 28 \\
\hline & & & & & & & & $F 21$ & 0.2479 & 3 & 0.0237 & 19 \\
\hline & & & & & & & & $F 22$ & 0.1435 & 4 & 0.0137 & 26 \\
\hline & & & $F 2$ & 0.2169 & 3 & 0.0957 & 6 & $F 23$ & 0.0962 & 5 & 0.0092 & 29 \\
\hline & & & & & & & & $F 24$ & 0.2523 & 2 & 0.0241 & 18 \\
\hline & & & & & & & & $F 25$ & 0.2601 & 1 & 0.0249 & 17 \\
\hline & & & & & & & & F31 & 0.3847 & 1 & 0.0470 & 6 \\
\hline & & & & & & & & F32 & 0.1433 & 4 & 0.0175 & 24 \\
\hline & & & F3 & 0.2767 & 2 & 0.1221 & 5 & F33 & 0.2633 & 2 & 0.0321 & 12 \\
\hline & & & & & & & & F34 & 0.2086 & 3 & 0.0255 & 15 \\
\hline & & & & & & & & $F 41$ & 0.2894 & 2 & 0.0189 & 22 \\
\hline & & & & & & & & $F 42$ & 0.2361 & 3 & 0.0154 & 25 \\
\hline & & & $F 4$ & 0.1480 & 4 & 0.0653 & 7 & $F 43$ & 0.0855 & 4 & 0.0056 & 32 \\
\hline & & & & & & & & F44 & 0.3890 & 1 & 0.0254 & 16 \\
\hline & & & & & & & & $F 51$ & 0.2138 & 3 & 0.0054 & 33 \\
\hline & & & & & & & & F52 & 0.3541 & 1 & 0.0090 & 30 \\
\hline & & & F5 & 0.0573 & 5 & 0.0253 & 8 & F53 & 0.2976 & 2 & 0.0075 & 31 \\
\hline & & & & & & & & F54 & 0.1346 & 4 & 0.0034 & 34 \\
\hline
\end{tabular}

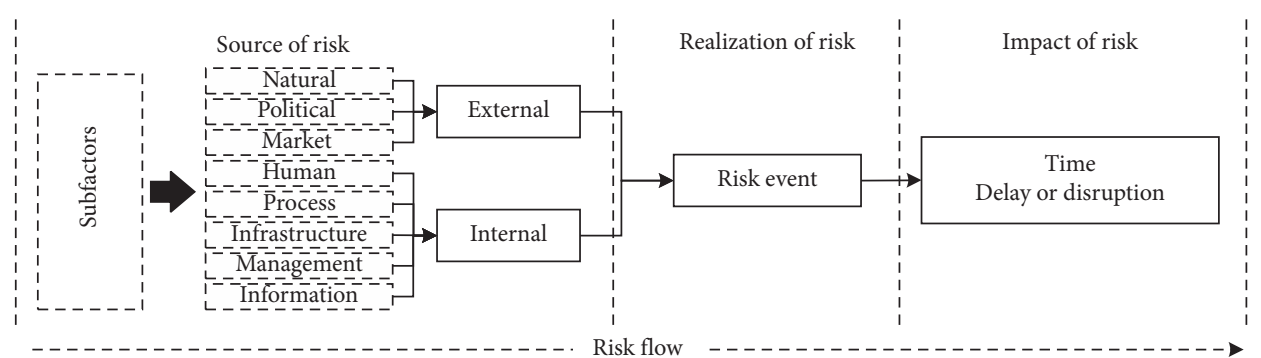

FIgUre 3: The delay or disruption risk path in PHSN.

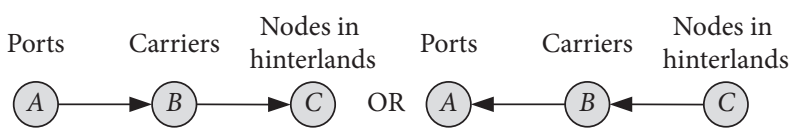

FIGURE 4: Chained risk propagation diagram.

$\lim _{t \longrightarrow+\infty} S(t)=K$. Suppose the market capacities of the carrier and the port are $K_{1}$ and $K_{2}$, respectively; then, their growth rates are $r_{1}$ and $r_{2}$, respectively.
4.2. Model Building and Solving. From dynamic and systemic perspectives, port-hinterland service networks can be considered dynamic complex systems. The SIR model, a 


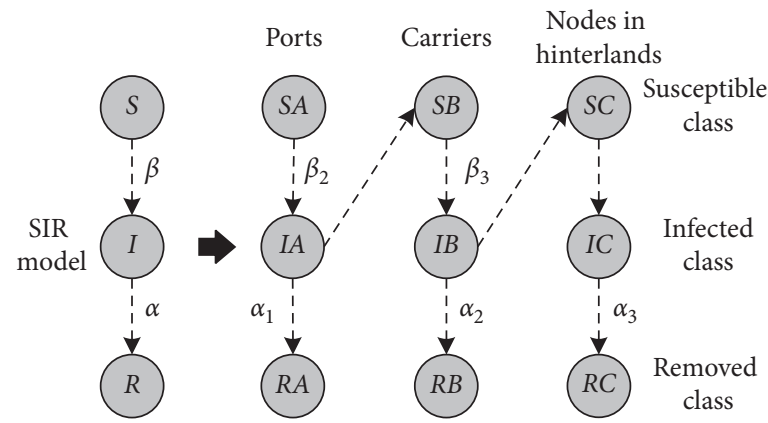

FiguRE 5: Chained risk propagation diagram in the port-hinterland service network.

classic method in epidemic research, is widely used in supply chain risk propagation, information spread, etc., and differential equations are the main method to analyse the dynamic system, so we combine the SIR model and differential equation method together in our study. As demonstrated in Figure 5, the nonlinear dynamic system model for risk propagation in the port-hinterland service network is built:

$$
\begin{aligned}
& D_{B}=\left\{\begin{array}{l}
\frac{\mathrm{d} S_{B}}{\mathrm{~d} t}=r_{1} S_{B}\left(1-\frac{S_{B}}{K_{1}}\right)-\beta_{2} I_{A} S_{B}, \\
\frac{\mathrm{d} I_{B}}{\mathrm{~d} t}=\beta_{2} I_{A} S_{B}-\alpha_{2} I_{B}, \\
\frac{\mathrm{d} R_{B}}{\mathrm{~d} t}=\alpha_{2} I_{B},
\end{array}\right. \\
& D_{C}=\left\{\begin{array}{l}
\frac{\mathrm{d} S_{C}}{\mathrm{~d} t}=r_{2} S_{C}\left(1-\frac{S_{C}}{K_{2}}\right)-\beta_{3} I_{B} S_{C}, \\
\frac{\mathrm{d} I_{C}}{\mathrm{~d} t}=\beta_{3} I_{B} S_{C}-\alpha_{3} I_{C}, \\
\frac{\mathrm{d} R_{C}}{\mathrm{~d} t}=\alpha_{3} I_{C} .
\end{array}\right.
\end{aligned}
$$

The nonlinear dynamic system model for risk propagation in the port-hinterland service network comprises nonlinear dynamic system models $D_{B}$ and $D_{C}$, namely, $\left\{\begin{array}{l}D_{B} \\ D_{C}\end{array}\right.$. For the model structure, the chained risk propagation model is a six-dimensional system. It might be complicated to figure out the features of the dynamics. Therefore, the model can be rewritten as follows. Since the first two differential equations of models $D_{B}$ and $D_{C}$ do not include the variable $R_{B}$ and $R_{C}$, the model above can be rewritten as a four-dimensional nonlinear dynamic system:

$$
\left\{\begin{array}{l}
\frac{\mathrm{d} S_{B}}{\mathrm{~d} t}=r_{1} S_{B}\left(1-\frac{S_{B}}{K_{1}}\right)-\beta_{2} I_{A} S_{B} \\
\frac{\mathrm{d} I_{B}}{\mathrm{~d} t}=\beta_{2} I_{A} S_{B}-\alpha_{2} I_{B} \\
\frac{\mathrm{d} S_{C}}{\mathrm{~d} t}=r_{2} S_{C}\left(1-\frac{S_{C}}{K_{2}}\right)-\beta_{3} I_{B} S_{C} \\
\frac{\mathrm{d} I_{C}}{\mathrm{~d} t}=\beta_{3} I_{B} S_{C}-\alpha_{3} I_{C}
\end{array}\right.
$$

To explore the nature of this dynamic system, the equilibrium point is first calculated based on the ordinary differential equation (ODE) theory. Letting the right side of each differential equation (2) be equal to zero, we can obtain the following equation:

$$
\left\{\begin{array}{l}
r_{1} S_{B}\left(1-\frac{S_{B}}{K_{1}}\right)-\beta_{2} I_{A} S_{B}=0 \\
\beta_{2} I_{A} S_{B}-\alpha_{2} I_{B}=0 \\
r_{2} S_{C}\left(1-\frac{S_{C}}{K_{2}}\right)-\beta_{3} I_{B} S_{C}=0 \\
\beta_{3} I_{B} S_{C}-\alpha_{3} I_{C}=0 .
\end{array}\right.
$$

Considering in reality, $S_{B}>0, I_{B}>0, S_{C} \geq 0$, and $I_{C} \geq 0$, we can obtain four equilibrium points within the positive feasible domain: $Z_{1}=(0,0,0,0) Z_{2}=\left(0,0, k_{2}, 0\right)$, $Z_{3}=\left(k_{1}\left(-\beta_{2} I_{A}+r_{1}\right) / r_{1}, \beta_{2} \quad I_{A} k_{1}\left(-\beta_{2} I_{A} \quad+r_{1}\right) / a_{2} r_{1}, 0,0\right)$ $Z_{4}=\left(S_{B}^{*}, I_{B}^{*}, S_{C}^{*}, I_{C}^{*}\right)$, where

$$
\begin{aligned}
& S_{B}^{*}=\frac{k_{1}\left(-\beta_{2} I_{A}+r_{1}\right)}{r_{1}}, I_{B}^{*}=\frac{\beta_{2} I_{A} k_{1}\left(-\beta_{2} I_{A}+r_{1}\right)}{\alpha_{2} r_{1}}, \\
& S_{C}^{*}=\frac{k_{2}\left(\alpha_{2} r_{1} r_{2}+\beta_{2}^{2} \beta_{3} I_{A}^{2} k_{1}-\beta_{2} \beta_{3} I_{A} k_{1} r_{1}\right)}{\alpha_{2} r_{1} r_{2}},
\end{aligned}
$$




$$
I_{C}^{*}=\frac{\beta_{2} \beta_{3} I_{A} k_{1} k_{2}\left(-\beta_{2} I_{A}+r_{1}\right)\left(\alpha_{2} r_{1} r_{2}+\beta_{2}^{2} \beta_{3} I_{A}^{2} k_{1}-\beta_{2} \beta_{3} I_{A} k_{1} r_{1}\right)}{\alpha_{2}^{2} \alpha_{3} r_{1}^{2} r_{2}} .
$$

4.3. Steady-State Analysis. There are four equilibrium points in the process of risk propagation in the port-hinterland service network. The state of those four equilibrium points in this dynamic system determines the final state of the risk propagation in the port-hinterland service network. If one equilibrium point is steady, it indicates that when the porthinterland service network meets the steady conditions of that equilibrium, the risk will not diffuse in the PHSN, and the proportion of participants with risk will no longer increase, meaning that the risk is under control. Here, we determine and analyse the equilibrium points and their stability, and dynamic system (2) is as follows:

$$
\left\{\begin{array}{l}
r_{1} S_{B}\left(1-\frac{S_{B}}{K_{1}}\right)-\beta_{2} I_{A} S_{B}=M\left(S_{B}, I_{B}, S_{C}, I_{C}\right) \\
\beta_{2} I_{A} S_{B}-\alpha_{2} I_{B}=N\left(S_{B}, I_{B}, S_{C}, I_{C}\right) \\
r_{2} S_{C}\left(1-\frac{S_{C}}{K_{2}}\right)-\beta_{3} I_{B} S_{C}=P\left(S_{B}, I_{B}, S_{C}, I_{C}\right) \\
\beta_{3} I_{B} S_{C}-\alpha_{3} I_{C}=Q\left(S_{B}, I_{B}, S_{C}, I_{C}\right)
\end{array}\right.
$$

The Jacobi matrix of system (4) is as follows:

$$
J=\left[\begin{array}{cccc}
-\beta_{2} I_{A}+r_{1}\left(1-\frac{S_{B}}{k_{1}}\right)-\frac{r_{1} S_{B}}{k_{1}} & 0 & 0 & 0 \\
\beta_{2} I_{A} & -\alpha_{2} & 0 & 0 \\
0 & -\beta_{3} S_{C}-\beta_{3} I_{B}+r_{2}\left(1-\frac{S_{C}}{k_{2}}\right)-\frac{r_{2} S_{C}}{k_{2}} & 0 \\
0 & \beta_{3} S_{C} & \beta_{3} I_{B} & -\alpha_{3}
\end{array}\right]
$$

(1) Associate the equilibrium point $Z_{1}$ with Jacobi matrix $J$ and its characteristic matrix:

$$
\begin{aligned}
\left|\lambda E-J_{Z}\right| & =\left|\begin{array}{cccc}
\lambda-r_{1}+\beta_{2} I_{A} & 0 & 0 & 0 \\
\beta_{2} I_{A} & \lambda+\alpha_{2} & 0 & 0 \\
0 & 0 & \lambda-r_{2} & 0 \\
0 & 0 & 0 & \lambda+\alpha_{3}
\end{array}\right| \\
& =\left(\lambda-r_{1}+\beta_{2} I_{A}\right) \cdot\left(\lambda+\alpha_{2}\right) \cdot\left(\lambda-r_{2}\right) \cdot\left(\lambda+\alpha_{3}\right) .
\end{aligned}
$$

Let $\left|\lambda E-J_{Z}\right|=0$, and we can obtain four eigenvalues of Jacobi matrix $J$ at equilibrium point $Z_{1}$, respectively:

$$
\lambda_{1}=-\alpha_{2}, \lambda_{2}=-\alpha_{3}, \lambda_{3}=r_{2}, \lambda_{4}=r_{1}-\beta_{2} I_{A} .
$$

Since $r_{2}>0$, the equilibrium point $Z_{1}$ is the unstable point.

(2) Associate the equilibrium point $Z_{2}$ with Jacobi matrix $J$ and its characteristic matrix $\left|\lambda E-J_{Z}\right|$ :

$\left(\lambda-r_{1}+\beta_{2} I_{A}\right) \cdot\left(\lambda+\alpha_{2}\right) \cdot\left(\lambda+r_{2}\right) \cdot\left(\lambda+\alpha_{3}\right)$.

By making $\left|\lambda E-J_{Z}\right|=0$, we can obtain four eigenvalues of the equilibrium point $Z_{2}$, respectively:

$\lambda_{1}=-\alpha_{2}, \lambda_{2}=-\alpha_{3}, \lambda_{3}=-r_{2}, \lambda_{4}=r_{1}-\beta_{2} I_{A}$.
Let $R_{1}=r_{1} / \beta_{2} I_{\mathrm{A}}$. When $R_{1}<1$, the equilibrium point $Z_{2}$ is a locally asymptotically stable point, and when $R_{1}>1, Z_{2}$ is an unstable point.

(3) Associate the equilibrium point $Z_{3}$ with Jacobi matrix $J$ and its characteristic matrix $\left|\lambda E-J_{Z}\right|$ :

$\left(\lambda+r_{1}-\beta_{2} I_{A}\right) \cdot\left(\lambda+\alpha_{2}\right)$

$\cdot\left(\lambda-\left(r_{2}-\frac{k_{1} \beta_{2} \beta_{3} I_{A}\left(r_{1}-\beta_{2} I_{A}\right)}{\alpha_{2} r_{1}}\right)\right) \cdot\left(\lambda+\alpha_{3}\right)$.

By making $\left|\lambda E-J_{Z}\right|=0$, we can obtain four eigenvalues of the equilibrium point $Z_{3}$, respectively. Let $R_{2}=\alpha_{2} r_{1} r_{2} / \beta_{2} \beta_{3} I_{A} k_{1}\left(r_{1}-\beta_{2} I_{A}\right)$. When $R_{2}<1$, the equilibrium point $Z_{3}$ is a locally asymptotically stable point.

(4) Associate the equilibrium point $Z_{4}$ with Jacobi matrix $J$ and its characteristic matrix $\left|\lambda E-J_{Z}\right|$ :

$$
\begin{aligned}
& \left(\lambda+r_{1}-\beta_{2} I_{A}\right) \cdot\left(\lambda+\alpha_{2}\right) \\
& \cdot\left(\lambda+\frac{\alpha_{2} r_{1} r_{2}+\beta_{2}^{2} \beta_{3} I_{A}^{2} k_{1}-\beta_{2} \beta_{3} I_{A} k_{1} r_{1}}{\alpha_{2} r_{1}}\right) \cdot\left(\lambda+\alpha_{3}\right) .
\end{aligned}
$$

By making $\left|\lambda E-J_{Z}\right|=0$, we can obtain four eigenvalues of the equilibrium point $Z_{4}$, respectively. Since $\alpha_{2}>0, \alpha_{3}>0$, 
and $\left(r_{1}-\beta_{2} I_{A}\right)>0$, then $\lambda_{1}<0, \lambda_{2}<0, \lambda_{4}<0$. Let $R_{1}=r_{1} / \beta_{2} I_{A}$ and $R_{2}=\alpha_{2} r_{1} r_{2} / \beta_{2} \beta_{3} I_{A} k_{1}\left(r_{1}-\beta_{2} I_{A}\right)$. When $R_{2}>1$, the equilibrium point $Z_{4}$ is a locally asymptotically stable point.

From the analysis above, we obtain the following results:

(1) The equilibrium point $Z_{1}$ is unstable. This indicates the risk accompanies with port-hinterland service network forever, when the participant's conditions or external environment become unfavourable, the fluctuation of PHSN system will increase with the growth infection rate of the participants in PHSN.

(2) When $R_{1}<1$, the equilibrium point $Z_{2}$ is the only locally asymptotically stable point. In other words, the infected proportion of the carrier and the node in hinterland will decline and finally equals zero at $t \longrightarrow+\infty$, which means the risk in PHSN will disappear along with the time.

(3) When $R_{2}<1$, the equilibrium point $Z_{3}$ is the only locally asymptotically stable point. When the system is in a stable state, the infected proportion of the carrier will not become zero as time goes by. Instead, it reaches a fixed proportion $\beta_{2} I_{A} k_{1}\left(r_{1}-\beta_{2} I_{A}\right) / \alpha_{2} r_{1}$, and it indicates that risk hide in carriers with a fixed level and the risk will propagate again when its environment becomes unfavourable. The infected proportion of the node in hinterland is reduced gradually and finally equals zero. When the infected proportion of carriers becomes stable and other variables remain unchangeable, then the proportion can be calculated through a convex function $f\left(I_{A}\right)$ on $I_{A} . I_{A}$ reaches the maximum when $I_{A}=r_{1} / 2 \beta_{2}$. In other words, if the equilibrium point $Z_{3}$ exists, when $I_{A}<r_{1} / 2 \beta_{2}, f\left(I_{A}\right)$ is monotonically increasing as $I_{A}$ becomes higher. When $I_{A}>r_{1} / 2 \beta_{2}$, the $f\left(I_{A}\right)$ value monotonically decreases as $I_{A}$ becomes higher.

(4) When $R_{2}>1$, the equilibrium point $Z_{4}$ is the only locally asymptotically stable point. When the system is in a stable state, the infection rate of the carrier will exist and converge to $I_{B}^{*}$ and $I_{C}^{*}$. When other variables remain unchangeable, then the proportion can be calculated through a convex function $g\left(I_{A}\right)$ on $I_{A}$. It reaches the maximum when $I_{A}=r_{1} / 2 \beta_{2}$. In other words, if the equilibrium point $Z_{4}$ exists, when $I_{A}<r_{1} / 2 \beta_{2}, g\left(I_{A}\right)$ is monotonically increasing as $I_{A}$ becomes higher. When $I_{A}>r_{1} / 2 \beta_{2}, g\left(I_{A}\right)$ is monotonically decreasing as the value of $I_{A}$ becomes higher and the changes in $I_{C}^{*}$ are consistent with those of $I_{B}^{*}$.

\section{Optimal Risk Control Strategy Analysis}

To control the number of infected companies in the porthinterland service network and recover the port-hinterland service network ability, from the analysis of $R_{1}=r_{1} / \beta_{2} I_{A}$, $R_{2}=\alpha_{2} r_{1} r_{2} / \beta_{2} \beta_{3} I_{A} k_{1}\left(r_{1}-\beta_{2} I_{A}\right)$ a lower infection rate $\beta_{2}$, $\beta_{3}$, and $I_{A}$ or a higher recovery rate $\alpha_{2}$ and $\alpha_{3}$ can effectively control the proportion of infected companies. However, we still do not know what measure is the most effective to reduce risks. To determine the optimal risk control strategy, this paper applies the elastic theory analysis method in an economics study by comparing the elasticity of equilibrium points on $\beta_{2}, \beta_{3}, I_{A}, \alpha_{2}$, and $\alpha_{3}$. Since the equilibrium point $Z_{2}$ is a no-epidemic stable point, this paper only analyses the elasticity of $I_{B}$ and $I_{C}$ to $I_{A}, \beta_{2}, \beta_{3}, \alpha_{2}$, and $\alpha_{3}$ when the equilibrium points $Z_{3}$ and $Z_{4}$ are in a stable state. The detailed analysis is as follows:

(1) Elasticity analysis of the equilibrium point $Z_{3}$

The elasticity coefficients of $I_{B}$ to $I_{A}$ and $\beta_{2}$ are, respectively,

$$
\tau_{I_{A}}=\frac{2 \beta_{2} I_{A}-r_{1}}{\beta_{2} I_{A}-r_{1}}, \tau_{\beta_{2}}=\frac{2 \beta_{2} I_{A}-r_{1}}{\beta_{2} I_{A}-r_{1}} .
$$

Since $\left(-\beta_{2} I_{A}+r_{1}\right)>0$, when $I_{A}>r_{1} / 2 \beta_{2}, \tau_{I_{A}}>0$ and $\tau_{\beta_{2}}>0$. The elasticity coefficient of $I_{B}$ to $\alpha_{2}$ is $\tau_{\alpha_{2}}=-1$. Comparing the elasticity coefficient of $I_{B}$ to $\beta_{2}$ and $I_{B}$ to $\alpha_{2}$, we can see $\left|\tau_{\beta_{2}} / \tau_{\alpha_{2}}\right|<1$, namely, $\tau_{\beta_{2}}<\tau_{\alpha_{2}}$. Similarly, we can prove $\tau_{I_{A}}<\tau_{\alpha_{2}}$. Therefore, increasing the value of $\alpha_{2}$ will gain better effects than controlling the values of $\beta_{2}$ and $I_{A}$.

(2) Elasticity analysis of the equilibrium point $Z_{4}$

(1) In this stable state, $I_{B}^{*}=\beta_{2} I_{A} k_{1}\left(-\beta_{2} I_{A}+r_{1}\right) / \alpha_{2} r_{1}$, and its elasticity to $I_{A}, \beta_{2}$, and $\alpha_{2}$ is consistent with the elasticity of $I_{B}$ to $I_{A}, \beta_{2}$, and $\alpha_{2}$ at the equilibrium point $Z_{3}$.

(2) The elasticity coefficient of $I_{C}$ to $I_{A}$ is

$$
\tau_{I_{A}}^{\prime}=\frac{\left(-2 \beta_{2} I_{A}+r_{1}\right)\left(\alpha_{2} r_{1} r_{2}+2 \beta_{2}^{2} \beta_{3} I_{A}^{2} k_{1}-2 \beta_{2} \beta_{3} I_{A} k_{1} r_{1}\right)}{\left(-\beta_{2} I_{A}+r_{1}\right)\left(\alpha_{2} r_{1} r_{2}+\beta_{2}^{2} \beta_{3} I_{A}^{2} k_{1}-\beta_{2} \beta_{3} I_{A} k_{1} r_{1}\right)} \text {. }
$$

When $0<I_{A}<r_{1} / 2 \beta_{2}$ or $I_{A}>r_{1} / 2 \beta_{2}+\sqrt{r_{1}\left(-2 \alpha_{2} r_{2}+\right.}$ $\left.\beta_{3} k_{1} r_{1}\right) / 2 \beta_{2} \sqrt{\beta_{3} k_{1}}, \tau_{I A}^{\prime}>0$. When $r_{1} / 2 \beta_{2}<I_{A}<r_{1} / 2$ $\beta_{2}+\sqrt{r_{1}\left(-2 \alpha_{2} r_{2}+\beta_{3} k_{1} r_{1}\right)} / 2 \beta_{2} \sqrt{\beta_{3} k_{1}}, \tau_{I A}^{\prime}<0$.

The elasticity coefficient of $I_{C}$ to $\beta_{3}$ is

$$
\tau_{\beta_{3}}^{\prime}=\frac{\alpha_{2} r_{1} r_{2}+2 \beta_{2}^{2} \beta_{3} I_{A}^{2} k_{1}-2 \beta_{2} \beta_{3} I_{A} k_{1} r_{1}}{\alpha_{2} r_{1} r_{2}+\beta_{2}^{2} \beta_{3} I_{A}^{2} k_{1}-\beta_{2} \beta_{3} I_{A} k_{1} r_{1}} .
$$

When $\beta_{2}>\alpha_{2} r_{1} r_{2} / 2 \beta_{2} I_{A} k_{1}\left(-\beta_{2} I_{A}+r_{1}\right), \tau_{\beta_{3}}^{\prime}>0$. The elasticity coefficient of $I_{C}$ to $I_{A}$ is $\tau_{\alpha_{3}}^{\prime}=-1$. Comparing the elasticity coefficient of $I_{C}$ to $\beta_{3}$ and $I_{C}$ and $\alpha_{3}$, we can prove $\left|\tau_{\beta_{3}}{ }^{\prime} / \tau_{\alpha_{3}}{ }^{\prime}\right|<1$. Since $\left(-\beta_{2} I_{A}+r_{1}\right)<0$, then $\tau_{\beta_{3}}^{\prime}<\tau_{\alpha_{3}}^{\prime}$. Similarly, we can prove $\tau_{I_{A}}^{\prime}<\tau_{\alpha_{3}}^{\prime}$. Therefore, increasing the value of $\alpha_{3}$ will gain better effects than the control of $\beta_{3}$ and $I_{A}$ at the equilibrium point $Z_{4}$.

(3) The elasticity coefficient of $I_{C}$ to $\beta_{2}$ is

$\tau_{\beta_{2}}^{\prime \prime}=\frac{\left(-2 \beta_{2} I_{A}+r_{1}\right)\left(\alpha_{2} r_{1} r_{2}+2 \beta_{2}^{2} \beta_{3} I_{A}^{2} k_{1}-2 \beta_{2} \beta_{3} I_{A} k_{1} r_{1}\right)}{\left(-\beta_{2} I_{A}+r_{1}\right)\left(\alpha_{2} r_{1} r_{2}+\beta_{2}^{2} \beta_{3} I_{A}^{2} k_{1}-\beta_{2} \beta_{3} I_{A} k_{1} r_{1}\right)}$. 
When $0<\beta_{2}<r_{1} / 2 I_{A}$ or $\quad \beta_{2}>r_{1} / 2 I_{A}$
$+\sqrt{3 r_{1}\left(-2 \alpha_{2} r_{2}+\beta_{3} k_{1} r_{1}\right)} / 6 \sqrt{\beta_{3} k_{1}} I_{A}, \tau_{\beta_{2}}^{\prime \prime}>0$. When $r_{1} / 2 I_{A}<$
$\beta_{2}<r_{1} / 2 I_{A}+\sqrt{3 r_{1}\left(-2 \alpha_{2} r_{2}+\beta_{3} k_{1} r_{1}\right)} / 6 \sqrt{\beta_{3} k_{1}} I_{A}, \tau_{\beta_{2}}^{\prime \prime}<0$.
The elasticity coefficient of $I_{C}$ to $\alpha_{2}$ is

$$
\tau_{\alpha_{2}}^{\prime \prime}=-\frac{\alpha_{2} r_{1} r_{2}+2 \beta_{2}^{2} \beta_{3} I_{A}^{2} k_{1}-2 \beta_{2} \beta_{3} I_{A} k_{1} r_{1}}{\alpha_{2} r_{1} r_{2}+\beta_{2}^{2} \beta_{3} I_{A}^{2} k_{1}-\beta_{2} \beta_{3} I_{A} k_{1} r_{1}} .
$$

When $\alpha_{2}>2 \beta_{2} \beta_{3} I_{A} k_{1} r_{1}-2 \beta_{2}^{2} \beta_{3} I_{A}^{2} k_{1} / r_{1} r_{2}, \tau_{\alpha_{2}}^{\prime \prime}<0$, and otherwise, $\quad \alpha_{2}<2 \beta_{2} \beta_{3} I_{A} k_{1} r_{1}-2 \beta_{2}^{2} \beta_{3} I_{A}^{2} k_{1} / r_{1} r_{2}, \quad \tau_{\alpha_{2}}^{\prime \prime}>0$. Comparing the elasticity coefficient of $I_{C}$ to $\beta_{2}$ and $I_{C}$ to $\alpha_{2}$, we can prove $\left|\tau_{\beta_{2}}{ }^{\prime \prime} / \tau_{\alpha_{2}}{ }^{\prime \prime}\right|<1$ and $\tau_{\alpha_{2}}{ }^{\prime \prime}<\tau_{\alpha_{2}}{ }^{\prime} 0$. Therefore, we can see that improving the recovery rate of $\alpha_{2}$ is the most effective method of controlling $I_{C}$ in the stable state of the equilibrium point $Z_{4}$.

Through a comparison of the elasticities of $I_{B}$ and $I_{C}$ to $I_{A}, \beta_{2}, \beta_{3}, \alpha_{2}$, and $\alpha_{3}$ in the stable state of equilibrium points $Z_{3}$ and $Z_{4}$, we conclude that the elasticity of the recovery rate $\alpha$ is larger than that of the propagation rates $\beta$ and $I_{A}$, so increasing the recovery rate by one percent for each kind of participant compared with that of propagation rate and the infectious rate of ports can reduce the infectious proportion of agents in PHSNs by a greater extent. In other words, improving the recovery rate is the optimal choice for risk control in the port-hinterland service network.

\section{Optimal Investment Coefficient}

In the port-hinterland service network, a higher recovery rate of infected companies requires an investment of corresponding resources. A huge resource investment is critical for the recovery of the port logistics network, but too large on an investment will lead to a waste of resources. Especially, when the resources are limited, how to recover the port logistics network within a budget is what managers are concerned about.

From the proportion of infected companies when the system reaches a stable state, we deduce a rational budget for maintaining the port network function. Suppose the capital investment and recovery rate are marginally diminishing [53]. This paper sets the function of the capital investment and recovery rate as $\omega=\sqrt{2 / n} k^{1 / 2}$ and $k<\pi$, where $n$ denotes the marginal cost coefficients (the cost of producing one additional unit utility), $k$ is the capital input, and $\pi$ is the total capital. The constant $1 / 2$ is the elasticity of productivity of the input and is marginally diminishing. Let $\lambda>1$; if managers want to reduce the proportion of infected companies to $1 / \lambda$ of the initial number of infected companies by improving the recovery rate, a rational investment can be deduced to maintain the port-hinterland service network function at different levels.

(1) At the equilibrium point $Z_{3}$, the infected proportion of the carrier is $I_{B}=\beta_{2} I_{A} k_{1}\left(-\beta_{2} I_{A}+r_{1}\right) / \alpha_{2} r_{1}$. If managers want to reduce the proportion of infected carriers to $1 / \lambda$ of the initial number by improving the recovery rate, then $I_{B}^{\prime}=I_{B} / \lambda$, namely,

$$
\frac{\beta_{2} I_{A} k_{1}\left(-\beta_{2} I_{A}+r_{1}\right)}{\alpha_{2} r_{1}}=\frac{1}{\lambda} \times \frac{\beta_{2} I_{A} k_{1}\left(-\beta_{2} I_{A}+r_{1}\right)}{(1-\omega) \alpha_{2} r_{1}} .
$$

After solving, we can see $\omega=\lambda-1 / \lambda$ and the optimal investment in $\alpha_{2}$ is $n(\lambda-1)^{2} / 2 \lambda^{2}$.

(2) At the equilibrium point $Z_{4}$, the infected proportion of the carrier is

$$
I_{B}=\frac{\beta_{2} I_{A} k_{1}\left(-\beta_{2} I_{A}+r_{1}\right)}{\alpha_{2} r_{1}},
$$

and that of the port is

$$
I_{C}=\frac{\beta_{2} \beta_{3} I_{A} k_{1} k_{2} \beta\left(-b_{2} I_{A}+r_{1}\right)\left(\alpha_{2} r_{1} r_{2}+\beta_{2}^{2} \beta_{3} I_{A}^{2} k_{1}-\beta_{2} \beta_{3} I_{A} k_{1} r_{1}\right)}{\alpha_{2}^{2} \alpha_{3} r_{1}^{2} r_{2}} .
$$

In this way, we can calculate that the optimal investment in $\alpha_{2}$ and $\alpha_{3}$ is $n(\lambda-1)^{2} / 2 \lambda^{2}$, so it is helpful for the manager or participants of this port-hinterland service network to estimate the reasonable investment amount in risk control, which reduces the certain proportion of infectious agents along with the time that can keep the port-hinterland service network work stable, especially under the limitation of risk control resources.

\section{Model Validation}

Based on the theoretical analysis, to validate the effectiveness of the result and explain the actual significance of the model, this paper tests the model by adopting the simulation analysis method. Considering that each differential equation of this model contains some nonlinear compositions without expression solutions, this paper adopts the Runge-Kutta method to obtain a numerical solution to show the changes in $I_{B}$ and $I_{C}$ under variable conditions [54]. To make the simulation more pragmatic, when setting the variables, an actual case of a porthinterland service network in Northeastern China is selected, and relevant data of the port and the carrier from 2019 are retrieved from the Yearbook Ports of China, China Logistics Yearbook, and Northeastern China Statistical Yearbook. Data on the number of ports and carriers can also be accessed. Finally, we select all the logistics companies registered in these three provinces and other logistics companies having business in this area. The statistical results are shown in Table 4 , which shows that $k_{1}=260$ and $k_{2}=6$.

The infection rate variables $\beta_{2}$ and $\beta_{3}$ can be, respectively, represented by the correlation between nodes in the hinterlands and carriers, as well as that between the carriers and ports. This paper uses a multinomial logit model to calculate the choice probability between different type of companies, and then we use the average choice probability to represent the infection rate. The basic model is

$$
p_{i}=\frac{\exp \left(b v_{i}\right)}{\sum_{i=1}^{n} \exp \left(b v_{i}\right)}=\frac{1}{1+\sum_{i \neq j} \exp \left[b\left(v_{i}-v_{j}\right)\right]}
$$


TABLE 4: Statistical table of the ports and carriers.

\begin{tabular}{lcc}
\hline Ports & Dalian Port, Yingkou Port, Dandong Port, Jinzhou Port, Huludao Port, Panjin Port & 6 \\
\hline Carriers & CRCT, China Materials Storage and Transportation Group, JC TRANS, CIMC LOGISTICS, Dalian CRFS, REC & 21 \\
Nodes in hinterlands & Shenyang, Dalian, Changchun, Haerbin, Yingkou, Anshan, Siping & 35 \\
\hline
\end{tabular}

When nodes in the hinterlands select the carriers, five indicators can be considered, such as the registered capital, number of employees, number of years since the establishment of the company, whether it is owned by a person, another company, or the country, the distance between the carrier and the port, and the distance to the carrier. Because the choice probabilities of nodes in the hinterland can affect the carriers' choice probabilities, the relations between the carriers and ports are the product of the choice probability between nodes in the hinterlands and that between carriers and ports. For the choice probabilities between the nodes in the hinterlands and port and between carriers and ports, indicators such as the distance, the number of berths, port throughput, average ship loading and uploading capacity per hour, average drawbridge loading and uploading capacity per hour, the number of arrived ships, and the average days of containers delayed in the yard are involved.

After calculation, the approximations of the infection coefficients $\beta_{2}$ and $\beta_{3}$ are 0.376820 and 0.062159 , respectively. In addition, since the number of ports and carriers could remain stable over a period of time (especially the number of ports), the growth rate $r_{2}$ is set as 0.001 . The growth rate of carriers is higher than $r_{2}$ and is set as 0.005 . The recovery rates $\alpha_{2}$ and $\alpha_{3}$ are set as different values, which are consistent with different equilibrium conditions.

7.1. Simulation Results of System Stability. According to the analysis in 4.3 , when $R_{1}<1$, the equilibrium point $Z_{2}$ is the only locally asymptotically stable point; when $R_{2}<1$, the equilibrium point $Z_{3}$ is the only locally asymptotically stable point, and when $R_{2}>1$, the equilibrium point $Z_{4}$ is the only locally asymptotically stable point. Three different numerical analyses for each equilibrium scenario will be performed as follows:

(1) When $R_{1}<1$, the equilibrium point $Z_{2}$ is the only locally asymptotically stable point. The parameters and results are illustrated in Table 5 and Figure 6, respectively.

From the figure above, we can see that when $R_{1}<1$, the values of $I_{B}$ and $I_{C}$ approach zero. This shows that the infected proportion of carriers and ports gradually disappears as time goes by when risks occur. Under this condition, the risks are controllable.

(2) When $R_{2}<1$, the equilibrium point $Z_{3}$ is the only locally asymptotically stable point. Table 6 shows the variable setting as follows.
From Figure 7, we can see that when $R_{2}<1$, the value of $I_{B}$ approaches a constant that is not zero and $I_{C}$ approaches zero. This shows that the infected proportion of carriers in the port-hinterland service network always exists and reaches a stable state, while the infected proportion of ports gradually disappears as time goes by.

(3) When $R_{2}>1$, the equilibrium point $Z_{4}$ is the only locally asymptotically stable point. The variables are set in Table 7.

From Figure 8, we can see that when $R_{2}>1$, the values of $I_{B}$ and $I_{C}$ approach a constant that is not zero. This shows that an infected proportion of carriers and ports always exists and reaches a stable state.

7.2. Risk Control Simulation Analysis. Based on the numerical analysis in 7.1, the other variables remain unchanged, and the effectiveness of the risk control strategy is verified by improving the recovery rates of $\alpha_{2}$ and $\alpha_{3}$. Considering that the infected proportion is zero when the equilibrium point $Z_{2}$ is in a stable state, a risk control simulation analysis is performed only when the equilibrium points $Z_{3}$ and $Z_{4}$ are in a stable state. The variable settings and changes in the lines are as follows:

(1) When $R_{2}<1, I_{B}$ changes as $\alpha_{2}$ varies. The variable setting and results are illustrated in Table 8 and Figure 9, respectively.

(2) When $R_{2}>1, I_{B}$ changes as $\alpha_{2}$ varies. The variable setting and results are shown in Table 9 and Figure 10 , respectively.

(3) When $R_{2}>1, I_{C}$ changes as $\alpha_{2}$ varies. Table 10 shows the variable setting, and Figure 11 presents the results as follows.

As demonstrated by the simulation analysis of the model's stability and controllability, we concluded that the numerical analysis result is consistent with the theoretical analysis, which proves the effectiveness of the model. The analysis in Section 6.2 inferred that a higher recovery rate can effectively control the infected proportion of carriers and ports in a stable state. Combining the deduction method of the optimal investment coefficient and determination of the investment input function, the optimal investment coefficient for risk control in the stable state can be calculated. 
TABLe 5: Variable setting table when $R_{1}<1$.

\begin{tabular}{lcccccccrr}
\hline$Z_{2}$ & $I_{A}$ & $r_{1}$ & $r_{2}$ & $k_{1}$ & $k_{2}$ & $\beta_{2}$ & $\beta_{3}$ & $\alpha_{2}$ \\
\hline$Z 21$ & 1 & 0.005 & 0.001 & 21 & 6 & 0.376820 & 0.062159 & 0.545328 & 0.834233 \\
$Z 22$ & 1 & 0.005 & 0.001 & 21 & 6 & 0.376820 & 0.062159 & 0.355397 & 0.034259 \\
$Z 23$ & 1 & 0.005 & 0.001 & 21 & 6 & 0.376820 & 0.062159 & 0.190431 & 0.473126 \\
\hline
\end{tabular}
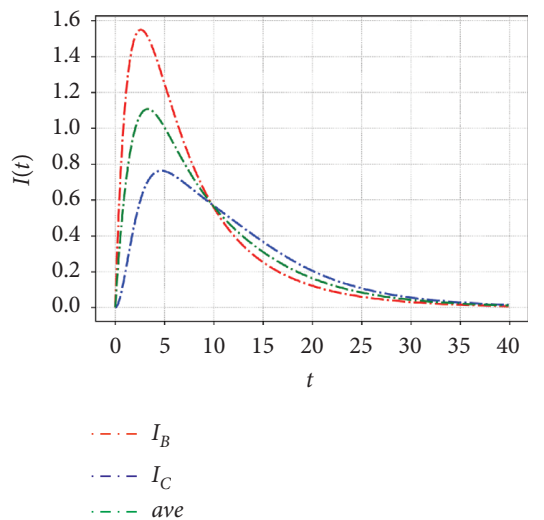

(a)
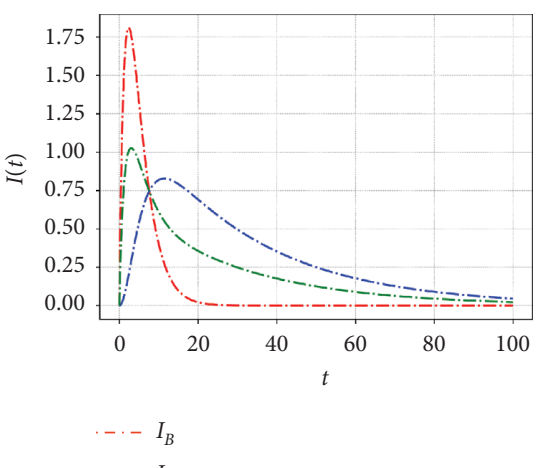

..- $I_{C}$

- ave

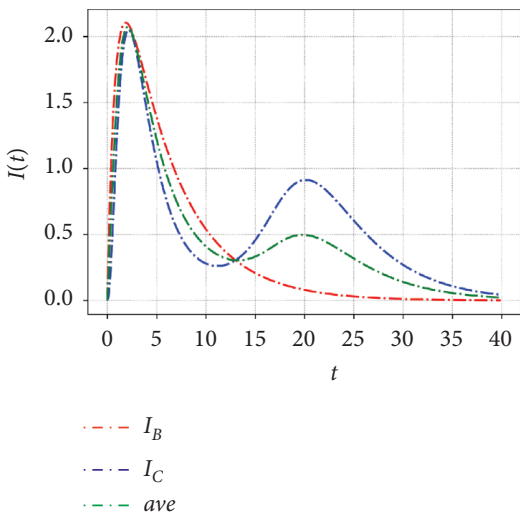

(c)

Figure 6: Changes of $I_{B}$ and $I_{C}$ when $R_{1}<1$.

TABle 6: Variable setting table when $R_{2}<1$.

\begin{tabular}{lcccccccrr}
\hline$Z_{2}$ & $I_{A}$ & $r_{1}$ & $r_{2}$ & $k_{1}$ & $k_{2}$ & $\beta_{2}$ & $\beta_{3}$ & $\alpha_{2}$ \\
\hline Z31 & 1 & 0.005 & 0.001 & 21 & 6 & 0.376820 & 0.062159 & 0.695143 & 0.984107 \\
Z32 & 1 & 0.005 & 0.001 & 21 & 6 & 0.376820 & 0.062159 & 0.640681 & 0.267727 \\
Z33 & 1 & 0.005 & 0.001 & 21 & 6 & 0.376820 & 0.062159 & 0.277766 & 0.309499 \\
\hline
\end{tabular}

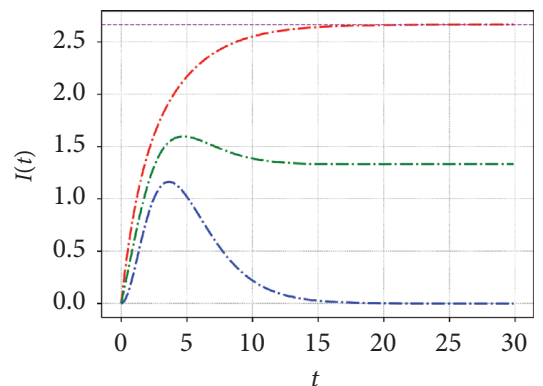

$\cdot \cdot \cdot-I_{B}$

... $I_{C}$

...- ave

(a)
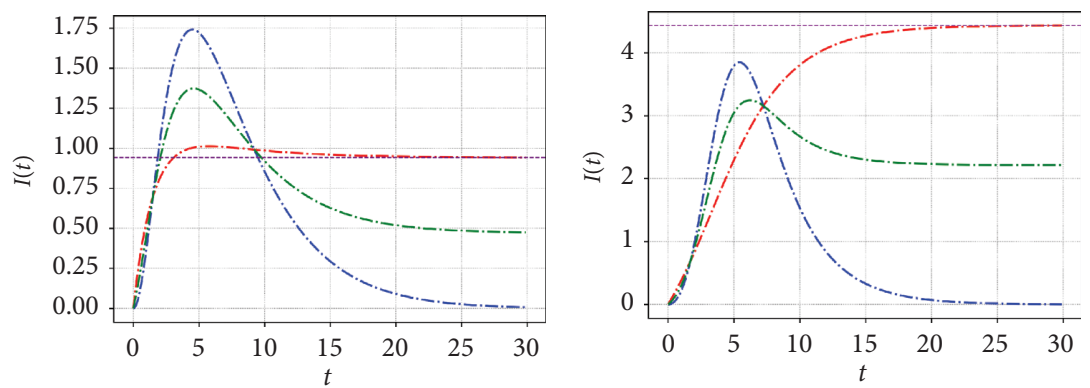

$\begin{array}{ll} & \\ \ldots & I_{B} \\ \ldots & I_{C} \\ \text {.. } & \text { ave }\end{array}$

(b) $\cdot-\cdot I_{B}$

... $I_{C}$

...- ave

(c)

FIgure 7: Changes of $I_{B}$ and $I_{C}$ when $R_{2}<1$.

TABle 7: Variable setting table when $R_{2}>1$.

\begin{tabular}{lccccccccc}
\hline$Z_{2}$ & $I_{A}$ & $r_{1}$ & $r_{2}$ & $k_{1}$ & $k_{2}$ & $\beta_{2}$ & $\beta_{3}$ & $\alpha_{2}$ \\
\hline Z41 & 1 & 0.0005 & 0.0001 & 21 & 6 & 0.376820 & 0.062159 & 0.706719 & 0.48044 \\
Z42 & 1 & 0.0005 & 0.0001 & 21 & 6 & 0.376820 & 0.062159 & 0.652378 & 0.63103 \\
Z43 & 1 & 0.0005 & 0.0001 & 21 & 6 & 0.376820 & 0.062159 & 0.898947 & 0.763014 \\
\hline
\end{tabular}




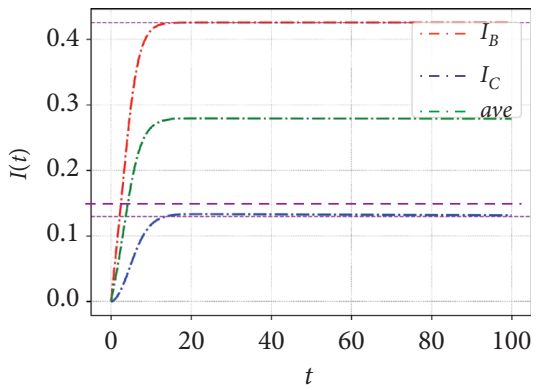

(a)

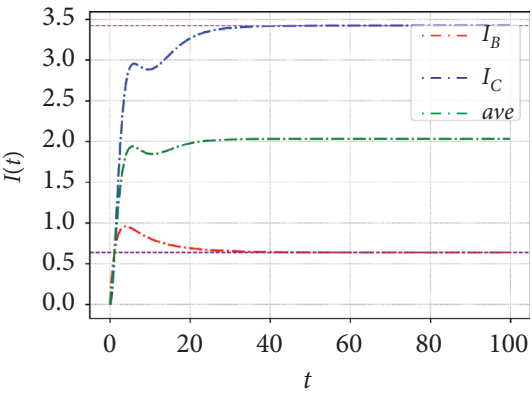

(b)

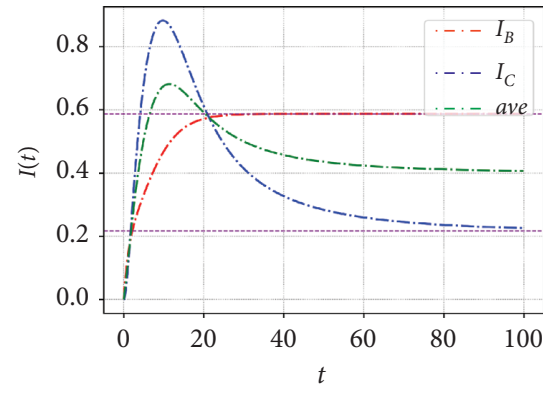

(c)

Figure 8: Changes of $I_{B}$ and $I_{C}$ when $R_{2}>1$.

TABLE 8: $\alpha_{2}{ }^{\prime}$ s variable setting when $R_{2}<1$.

\begin{tabular}{llll}
\hline Z31 & 0.695143 & 0.398246 & 0.228085 \\
\hline Z32 & 0.640681 & 0.263058 & 0.516978 \\
Z33 & 0.277766 & 0.574912 & 0.698571 \\
\hline
\end{tabular}

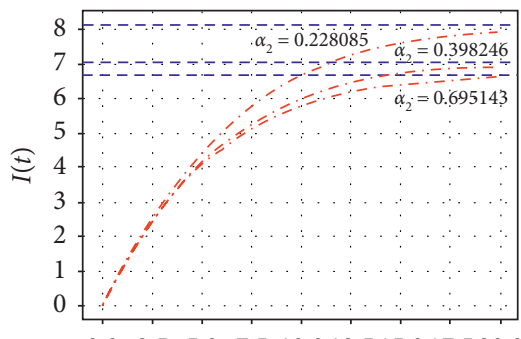

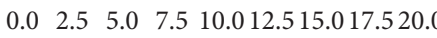

(a)

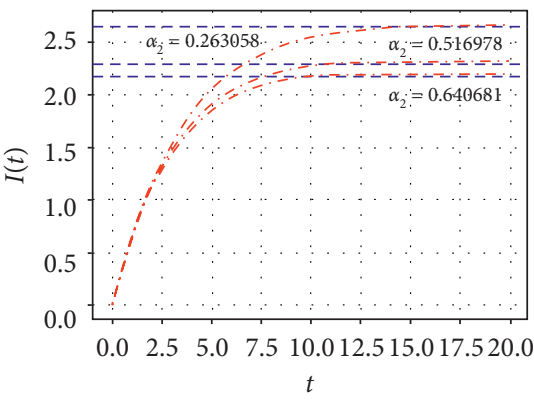

(b)

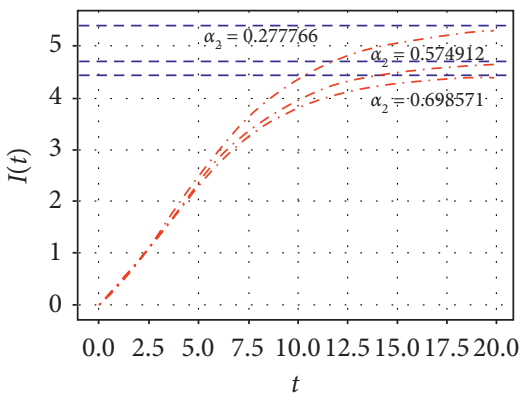

(c)

FIgURE 9: $I_{B}$ changes as $\alpha_{2}$ varies when $R_{2}<1$.

TABle 9: $\alpha_{2}^{\prime}$ s variable setting when $R_{2}>1$.

\begin{tabular}{llll}
\hline Z411 & 0.706719 & 0.567407 & 0.855854 \\
\hline Z412 & 0.652378 & 0.330679 & 0.832635 \\
Z413 & 0.898947 & 0.960666 & 0.825445 \\
\hline
\end{tabular}

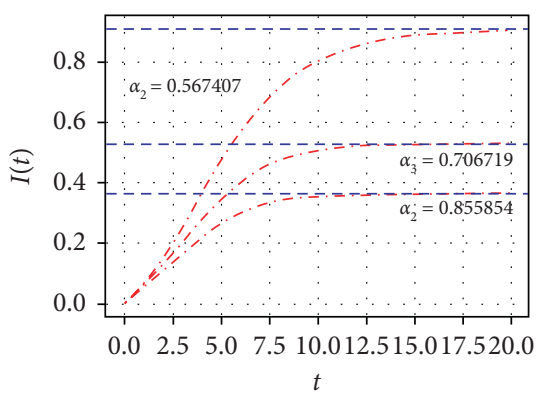

(a)

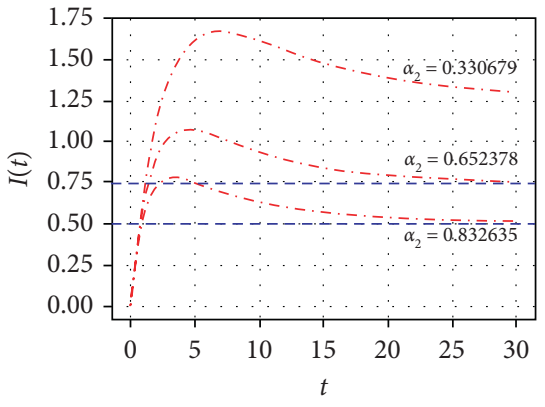

(b)

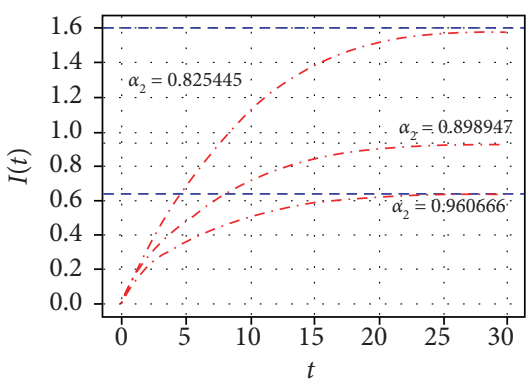

(c)

Figure 10: $I_{B}$ changes as $\alpha_{2}$ varies when $R_{2}>1$.

TABLE 10: $\alpha_{2}^{\prime}$ s variable setting when $R_{2}>1$.

\begin{tabular}{llll}
\hline Z421 & 0.48044 & 0.746125 & 0.17071 \\
\hline Z422 & 0.63103 & 0.252873 & 0.38213 \\
Z423 & 0.76301 & 0.225578 & 0.57613 \\
\hline
\end{tabular}




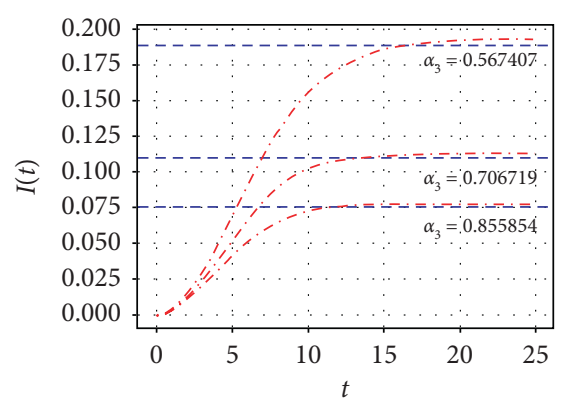

(a)

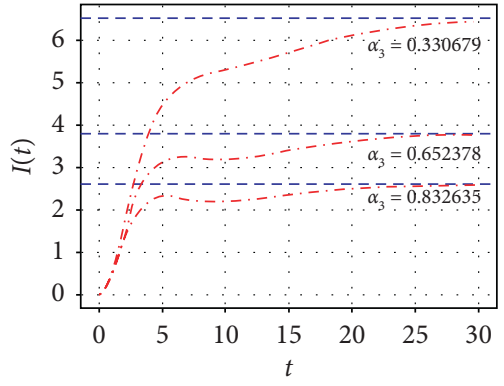

(b)

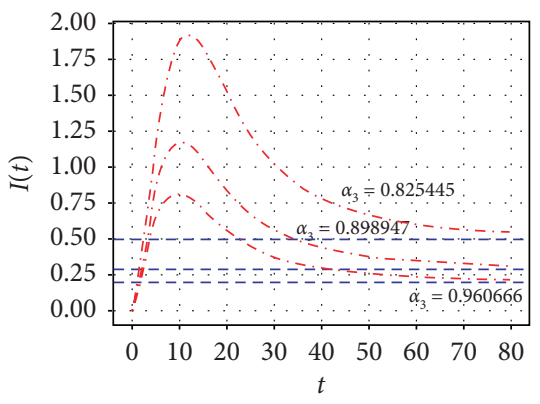

(c)

Figure 11: $I_{C}$ changes as $\alpha_{3}$ varies when $R_{2}>1$.

\section{Conclusions}

This paper conducted research on delay or disruption risk analysis, stability, controllability, optimal control strategy of risk propagation, and coefficients in a port-hinterland service network from the perspective of chained risk propagation. This paper provided a brand-new perspective on the research of risk propagation in a port-hinterland service network, offered insights to managers, and helped them with a better understanding of the risk generation and propagation process and risk control methods. The following conclusions can be drawn through the analysis:

(1) External factors are more important than internal factors in the delay or disruption generation process because external factors are not always under control and occur suddenly, while the occurrence probability of external factors is lower than that of internal factors. Among external factors, natural factors are the key to causing delay or disruption risks. The second most important category is political, and the next most important category is the market. Internal factors are also important aspects of delay or disruption risk, which comprise the descending importance rank factor, namely, human, infrastructure, process, management, and information.

(2) There are four equilibrium points in the chained risk propagation in the port-hinterland service network. There is only one no-epidemic equilibrium point, and all three equilibrium points are controllable. At the no-epidemic equilibrium point, the infected proportion of carriers and ports gradually decreases to zero or narrows down to a fixed ratio. At the other two equilibrium points, there are two different scenarios: the infection rate of the carriers becomes stable and the infected proportion of ports gradually decreases to zero over time. Moreover, infected carriers and ports always exist, and the infection rate narrows down to a fixed ratio.

(3) In the chained risk propagation process in the porthinterland service network, it is not the case where the higher the infected proportion of the hinterland is, the greater the impact it will exert on the carrier and the port's infected proportion. Instead, when the infected proportion of the hinterlands is lower than a certain threshold, the infected proportion of the hinterlands increases with an increase in the infection rate of the carriers and ports. When the infected proportion of the hinterlands is greater than a certain threshold, the infected proportion of the hinterlands decreases with an increase in the infected proportion of carriers and ports. Moreover, when the infection rate of the hinterlands equals a certain threshold, the infected proportion of the hinterlands has the greatest impact on the infected proportion of carriers and ports.

(4) Reducing the infection incidence between the hinterlands and carriers and between carriers and ports, decreasing the infection rate of the hinterlands, or improving the recovery rate of the carrier and the port will help control the risks in the port-hinterland service network. However, these measures may produce different effects. Through an analysis of the elasticity, improving the recovery rate is the most direct and effective method.

However, future research needs to explore the characteristics of the participants in the port-hinterland service network and risk propagation forms, such as the performance of China's special port enterprises in risk propagation and the impacts of centralized and decentralized spreading on risk propagation and control strategy. In this way, a more practical risk propagation model with a higher significance will be built.

\section{Data Availability}

The data used to support the findings of this study are available from the corresponding author upon request.

\section{Conflicts of Interest}

The authors declare that they have no conflicts of interest.

\section{Acknowledgments}

This work was supported by the National Key Research and Development Project (grant no.2019YFB1600401), Youth 
Program of the National Natural Science Foundation of China (grant no. 71503029), and the State Key Program of the National Natural Science of China (grant no.71831002).

\section{References}

[1] H. Chen, J. S. L. Lam, and N. Liu, "Strategic investment in enhancing port-hinterland container transportation network resilience: a network game theory approach," Transportation Research Part B: Methodological, vol. 111, pp. 83-112, 2018.

[2] K. A. O. Maarten Van De Voort, "Seacurity improving the security of the global sea-container shipping system," Rand Corporation, 2003.

[3] J. Liu and J. Wang, "Research on supervision problems of port hazards chemicals base on security risk level," System Engineering Theory and Practice, vol. 38, no. 5, pp. 1141-1152, 2018.

[4] N. Liu, Z. Gong, and X. Xiao, "Disaster prevention and strategic investment for multiple ports in a region: cooperation or not," Maritime Policy \& Management, vol. 45, no. 5, pp. 585-603, 2018.

[5] T. E. Notteboom, "The time factor in liner shipping services," Maritime Economics \& Logistics, vol. 8, no. 1, pp. 19-39, 2006.

[6] J. Vilko, P. Ritala, and J. Hallikas, "Risk management abilities in multimodal maritime supply chains: visibility and control perspectives," Accident Analysis \& Prevention, vol. 123, pp. 469-481, 2019.

[7] S. Gurning and S. Cahoon, "Analysis of multi-mitigation scenarios on maritime disruptions," Maritime Policy \& Management, vol. 38, no. 3, pp. 251-268, 2011.

[8] C.-H. Chang, J. Xu, and D.-P. Song, "An analysis of safety and security risks in container shipping operations: a case study of Taiwan," Safety Science, vol. 63, pp. 168-178, 2014.

[9] J. P. P. Vilko and J. M. Hallikas, "Risk assessment in multimodal supply chains," International Journal of Production Economics, vol. 140, no. 2, pp. 586-595, 2012.

[10] B. Jiang, "Supply chain risk assessment and control of port enterprises: qingdao port as case study," The Asian Journal of Shipping and Logistics, vol. 34, no. 3, pp. 198-208, 2018.

[11] Z. Yang, Z. Yang, J. Yin, and Z. Qu, “A risk-based game model for rational inspections in port state control," Transportation Research Part E: Logistics and Transportation Review, vol. 118, pp. 477-495, 2018.

[12] J. S. L. Lam, "Designing a sustainable maritime supply chain: a hybrid QFD-ANP approach," Transportation Research Part E: Logistics and Transportation Review, vol. 78, pp. 70-81, 2015.

[13] K. Chen, D. Chen, X. Sun, and Z. Yang, "Container Oceantransportation System Design with the factors of demand fluctuation and choice inertia of shippers," Transportation Research Part E: Logistics and Transportation Review, vol. 95, pp. 267-281, 2016.

[14] H. Chen, K. Cullinane, and N. Liu, "Developing a model for measuring the resilience of a port-hinterland container transportation network," Transportation Research Part E: Logistics and Transportation Review, vol. 97, pp. 282-301, 2017.

[15] W. K. Talley and M. Ng, "Note: determinants of cargo port, hinterland cargo transport and port hinterland cargo transport service chain choices by service providers," Transportation Research Part E: Logistics and Transportation Review, vol. 137, Article ID 101921, 2020.

[16] J. Liu, "Model of emergencies risk transmission in demandpull supply chain," Operations Research And Management Science, vol. 20, no. 5, pp. 14-19, 2011.
[17] Y. Cheng G,Qiu, "Research on the mode of the supply chain risk conduction," Wuhan Univer Sity of Technology, vol. 22, no. 2, pp. 36-41, 2009.

[18] S. Rezapour, J. K. Allen, and F. Mistree, "Uncertainty propagation in a supply chain or supply," Network, vol. 73, pp. 185-206, 2015.

[19] C. Wan, X. Yan, D. Zhang, Z. Qu, and Z. Yang, “An advanced fuzzy Bayesian-based FMEA approach for assessing maritime supply chain risks," Transportation Research Part E: Logistics and Transportation Review, vol. 125, pp. 222-240, 2019.

[20] N. S. F. A. Rahman, M. K. Othman, I. A. Sanusi, A. M. Arof, and A. Ismail, "Evaluation of delay factors on dry bulk cargo operation in Malaysia: a case study of kemaman port," The Asian Journal of Shipping and Logistics, vol. 35, no. 3, pp. 127-137, 2019.

[21] H. S. Loh, Q. Zhou, V. V. Thai, Y. D. Wong, and K. F. Yuen, "Fuzzy comprehensive evaluation of port-centric supply chain disruption threats," Ocean \& Coastal Management, vol. 148, pp. 53-62, 2017.

[22] H. S. Cho, J. S. Lee, and H. C. Moon, "Maritime risk in seaport operation: a cross-country empirical analysis with theoretical foundations," The Asian Journal of Shipping and Logistics, vol. 34, no. 3, pp. 240-247, 2018.

[23] S.-R. Fartaj, G. Kabir, V. Eghujovbo, S. M. Ali, and S. K. Paul, "Modeling transportation disruptions in the supply chain of automotive parts manufacturing company," International Journal of Production Economics, vol. 222, Article ID 107511, 2020.

[24] J. Kwesi-Buor, D. A. Menachof, and R. Talas, "Scenario analysis and disaster preparedness for port and maritime logistics risk management," Accident Analysis \& Prevention, vol. 123, pp. 433-447, 2019.

[25] J. S. L. Lam, "Disruption risks and mitigation strategies: an analysis of asian ports," Maritime Policy \& Management, vol. 42, no. 5, pp. 415-435, 2015.

[26] M. Gonzalez-Aregall and R. Bergqvist, "The role of dry ports in solving seaport disruptions: a Swedish case study," Journal of Transport Geography, vol. 80, Article ID 102499, 2019.

[27] A. Asadabadi and E. Miller-Hooks, "Maritime port network resiliency and reliability through co-opetition," Transportation Research Part E: Logistics and Transportation Review, vol. 137, Article ID 101916, 2020.

[28] S. Hosseini and K. Barker, "Modeling infrastructure resilience using Bayesian networks: a case study of inland waterway ports," Computers \& Industrial Engineering, vol. 93, pp. 252-266, 2016.

[29] S. A. Torabi, M. Baghersad, and S. A. Mansouri, "Resilient supplier selection and order allocation under operational and disruption risks," Transportation Research Part E: Logistics and Transportation Review, vol. 79, pp. 22-48, 2015.

[30] Y.-b. Xiao, X. Fu, A. K. Y. Ng, and A. Zhang, "Port investments on coastal and marine disasters prevention: economic modeling and implications," Transportation Research Part B: Methodological, vol. 78, pp. 202-221, 2015.

[31] N. Goldbeck, P. Angeloudis, and W. Ochieng, "Optimal supply chain resilience with consideration of failure propagation and repair logistics," Transportation Research Part E: Logistics and Transportation Review, vol. 133, Article ID 101830, 2020.

[32] T. Sawik, "A two-period model for selection of resilient multitier supply portfolio," International Journal of Production Research, vol. 58, no. 19, pp. 6043-6060, 2020. 
[33] T. Sawik, "Disruption mitigation and recovery in supply chains using portfolio approach," Omega, vol. 84, pp. 232248, 2019.

[34] T. Sawik, "Selection of a dynamic supply portfolio under delay and disruption risks," International Journal of Production Research, vol. 56, no. 1-2, pp. 760-782, 2017.

[35] T. Sawik, "A portfolio approach to supply chain disruption management," International Journal of Production Research, vol. 55, no. 7, pp. 1970-1991, 2017.

[36] L. a. Huo, H. Guo, Y. Cheng, and X. Xie, "A new model for supply chain risk propagation considering herd mentality and risk preference under warning information on multiplex networks," Physica A: Statistical Mechanics and Its Applications, vol. 545, Article ID 123506, 2020.

[37] Y. Li, C. W. Zobel, O. Seref, and D. Chatfield, "Network characteristics and supply chain resilience under conditions of risk propagation," International Journal of Production Economics, vol. 223, Article ID 107529, 2020.

[38] Y. Zhang and N. Yang, "Vulnerability analysis of interdependent R\&D networks under risk cascading propagation," Physica A: Statistical Mechanics and Its Applications, vol. 505, pp. 1056-1068, 2018.

[39] L. Tang, K. Jing, J. He, and H. E. Stanley, "Robustness of assembly supply chain networks by considering risk propagation and cascading failure," Physica A: Statistical Mechanics and Its Applications, vol. 459, pp. 129-139, 2016.

[40] H. Liu, N. Yang, Z. Yang, J. Lin, and Y. Zhang, "The impact of firm heterogeneity and awareness in modeling risk propagation on multiplex networks," Physica A: Statistical Mechanics and Its Applications, vol. 539, Article ID 122919, 2020.

[41] Z. Yang K,Zhang, "The research on mechanism of supply chain network risk based on complex network theory," Journal of Systems Science and Mathematical Sciences, vol. 33, no. 10, pp. 1224-1232, 2013.

[42] M. Zhan and J. Pan, "Simulation of BSR-RP model in supply chain network risk propagation," Computer Technology and Development, vol. 37, no. 3, pp. 1-9, 2020.

[43] X. Deng, X. Yang, Y. Zhang, Y. Li, and Z. Lu, "Risk propagation mechanisms and risk management strategies for a sustainable perishable products supply chain," Computers \& Industrial Engineering, vol. 135, pp. 1175-1187, 2019.

[44] M. D. Garvey, S. Carnovale, and S. Yeniyurt, "An analytical framework for supply network risk propagation: a Bayesian network approach," European Journal of Operational Research, vol. 243, no. 2, pp. 618-627, 2015.

[45] I. Heckmann, T. Comes, and S. Nickel, "A critical review on supply chain risk - definition, measure and modeling," Omega, vol. 52, pp. 119-132, 2015.

[46] D. Waters, "Supply chain risk management: vulnerability and resilience inlogistics," Kogan Page, 2007.

[47] A. Dineva, A. Mosavi, S. Faizollahzadeh Ardabili et al., "Review of soft computing models in design and control of rotating electrical machines," Energies, vol. 12, no. 6, p. 1049, 2019.

[48] S. Paul, G. Kabir, S. M. Ali, and G. Zhang, "Examining transportation disruption risk in supply chains: a case study from Bangladeshi pharmaceutical industry," Research in Transportation Business \& Management, vol. 37, Article ID 100485, 2020.

[49] X. Gou and J. S. L. Lam, "Risk analysis of marine cargoes and major port disruptions," Maritime Economics \& Logistics, vol. 21, no. 4, pp. 497-523, 2018.

[50] X. Yang, "Enterprise tacit knowledge propagation SIR model with consideration of forgetting mechanisms," Chinese
Journal of Management Science, vol. 27, no. 7, pp. 196-202, 2019.

[51] J. Wei and Y. Huang, "Public opinion transmission of microblog network based on improved SIR model," Information Science, vol. 37, no. 06, pp. 16-22, 2019.

[52] E. Avila-Vales and Á. G. C. Pérez, "Dynamics of a timedelayed SIR epidemic model with logistic growth and saturated treatment," Chaos, Solitons \& Fractals, vol. 127, pp. 55-69, 2019.

[53] J. Liu and J. Wang, "Carrier alliance incentive analysis and coordination in a maritime transport chain based on service competition," Transportation Research Part E: Logistics and Transportation Review, vol. 128, pp. 333-355, 2019.

[54] S. P. Rajasekar and M. Pitchaimani, "Ergodic stationary distribution and extinction of a stochastic SIRS epidemic model with logistic growth and nonlinear incidence," Applied Mathematics and Computation, vol. 377, Article ID 125143, 2020. 